\title{
Collapse of loose sand with the addition of fines: the role of particle shape
}

\author{
J. YANG ${ }^{*}$ and L. M. WEI*
}

This paper describes a fundamental study to explore the role of particle shape in the shear behaviour of mixtures of sand and fine particles (fines) through macro-scale and grain-scale laboratory experiments together with interpretations in the framework of critical state soil mechanics and conceptual micromechanics models. Two non-plastic fines of distinct shape (angular crushed silica fines and rounded glass beads) were added to two uniform quartz sands (Toyoura sand and Fujian sand) to produce four binary mixtures. Laboratory quantification of particle shape and size was conducted for both fines and sands, and a series of undrained triaxial tests was performed to investigate the overall response of the mixed soils at different percentages of fines. One of the significant findings is that the critical state friction angle of a mixed soil is affected not only by the shape of coarse particles but also by the shape of fine particles, and this shape effect is coupled with fines content. When a small amount of crushed silica fines was added to either Toyoura sand or Fujian sand, the critical state friction angle increased slightly with fines content; however, when a small amount of glass beads was added to either sand, the critical state friction angle decreased markedly with an increase in fines content. A new index, termed combined roundness, is proposed to account for the coupled effects of particle shape and fines content. The study also provides evidence showing that the undrained shear behaviour and collapsibility of a mixed soil are closely related to the shape of its constituent particles: a mixed soil containing rounded fines tends to exhibit higher susceptibility to collapse than a mixed soil containing angular fines of the same percentage, and this tendency will become more evident if the base sand is also composed of rounded particles. In addition, the study provides the first experimental evidence showing that the quasi-steady state marks a transition from a metastable to a stable microstructure. It is postulated that in a binary mixture composed of fine and coarse particles that are both rounded, the particles favour rolling, thus yielding a microstructure that is unstable, whereas in a binary mixture composed of fine and coarse particles that are both angular, the particles favour sliding rather than rolling, thus leading to a much more stable structure and response.

KEYWORDS: fabric/structure of soils; laboratory tests; liquefaction; sands; shear strength; silts
La présente communication décrit une étude fondamentale explorant le rôle de la forme des particules dans le comportement au cisaillement des mélanges de sable et de fines, par le biais d'expériences à macro-échelle et à échelle des grains, ainsi que des interprétations dans le cadre de la mécanique des sols à l'état critique et de modèles de micromécanique conceptuels. On a ajouté deux fines non plastiques de forme distincte (fines de silice concassées angulaires et perles de verre arrondies) à deux sables de quartz uniformes (sable de Toyoura et sable de Fujian) pour produire quatre mélanges binaires. On a procédé à une quantification en laboratoire de la forme et de la taille des particules sur les fines et les sables, ainsi qu'à une série d'essais triaxiaux non drainés pour examiner la réaction générale des sols mixtes, avec différents pourcentages de fines. Une des conclusions les plus significatives est que l'angle de friction à l'état critique d'un sol mixte est affecté non seulement par la forme de particules grossières, mais aussi par celle des particules fines, et cet effet de la forme vient s'ajouter à la teneur en fines. Lorsque l'on ajoute une petite quantité de fines de silice broyées dans du sable de Toyoura ou du sable de Fujian, l'angle de friction à l'état critique augmente légèrement avec la teneur en fines. On propose un nouvel indice, appelé arrondi mixte, afin de tenir compte des effets accouplés de la forme des particules et de la teneur en fines. Cette étude fournit également des éléments démontrant que le comportement au cisaillement non drainé et le repliage d'un sol mixte sont en rapport étroit avec la forme de ses particules constituantes: un sol mixte contenant des fines arrondies a tendance à être plus susceptible à l'écrasement qu'un sol mixte contenant des fines angulaires dans le même pourcentage; cette tendance deviendra plus évidente si le sable de base est également composé de particules arrondies. En outre, l'étude fournit la première démonstration expérimentale de la transition que marque l'état quasipermanent d'une microstructure métastable à une microstructure stable. On postule que dans un mélange binaire composé de particules fines et grossières arrondies, les particules favorisent le roulement, en produisant ainsi une microstructure instable, tandis qu'un mélange binaire composé de particules fines et grossières angulaires, ces particules favorisent le glissement plutôt que le roulement, en donnant lieu ainsi à une structure et une réaction beaucoup plus stables.

\section{INTRODUCTION}

There has been abundant evidence that loose, saturated sand, when subjected to monotonic shearing under undrained conditions, will undergo a sudden loss of strength and a rapid development of deformation (e.g. Casagrande, 1971; Castro et al., 1982; Ishihara, 1993; Yang, 2002). This collapse

Manuscript received 1 June 2011; revised manuscript accepted 21 March 2012. Published online ahead of print 10 September 2012.

Discussion on this paper closes on 1 May 2013, for further details see p. ii.

* Department of Civil Engineering, The University of Hong Kong. behaviour, known as flow or static liquefaction, can result in catastrophic consequences for geotechnical applications. When a liquefiable sand is mixed with some finer particles of silt or clay size (i.e. fines), the flow potential of the sand can be altered significantly. Experimental studies have produced valuable data showing the effect of fines on the shear behaviour of sands (e.g. Kuerbis et al., 1988; Georgiannou et al., 1990; Pitman et al., 1994; Zlatovic \& Ishihara, 1995; Lade \& Yamamuro, 1997; Thevanayagam et al., 2002; Ni et al., 2004; Murthy et al., 2007). Nevertheless, very diverse views exist as to whether the effect of fines is negative or beneficial for flow liquefaction resistance. 
For example, Pitman et al. (1994) carried out a series of undrained triaxial compression tests on loose Ottawa sand mixed with either crushed silica fines or kaolin of varying quantities (from $0 \%$ to $40 \%$ by weight), and concluded that the effect of both types of fines was a decrease in the collapsibility of the mixed soils (i.e. varying from Type II to Type III response, as shown schematically in Fig. 1). Kuerbis et al. (1988) arrived at similar conclusions in testing wellgraded mixtures of tailing sand and non-plastic fines in triaxial compression. However, based on their triaxial tests on a quartz sand mixed with kaolin, Georgiannou et al. (1990) arrived at an opposite conclusion: that the degree of brittleness or collapsibility of the mixed soil increased with an increase in clay content (i.e. varying from Type II to Type I response, as illustrated in Fig. 1). Furthermore, Georgiannou (2006) showed that adding a very small amount $(2.5 \%)$ of silt to a base sand resulted in a dramatic reduction of brittleness compared with the same sand mixed with kaolin, and postulated that the rotund silt particles, unlike platy clay particles, led to a more stable response. This result appears to contradict the finding of Pitman et al. (1994) that there is little difference between the results using either plastic kaolin or non-plastic fines. Also, the result differs from the conclusion of Murthy et al. (2007), derived from triaxial tests on a quartz sand mixed with up to $15 \%$ non-plastic silt, that the presence of small amounts of fines will not alter the nature and characteristics of the undrained behaviour of sand.

The controversial or even contradictory views and results in the literature indicate that the influence of fines remains an area of great difficulty and uncertainty. The problem is complex, because the mixtures of sand and fines are granular materials in nature, comprising discrete particles that interact with each other during shearing. Most previous work has tended to concentrate on the effect of fines content by testing specimens of sand mixed with a specific type of fines
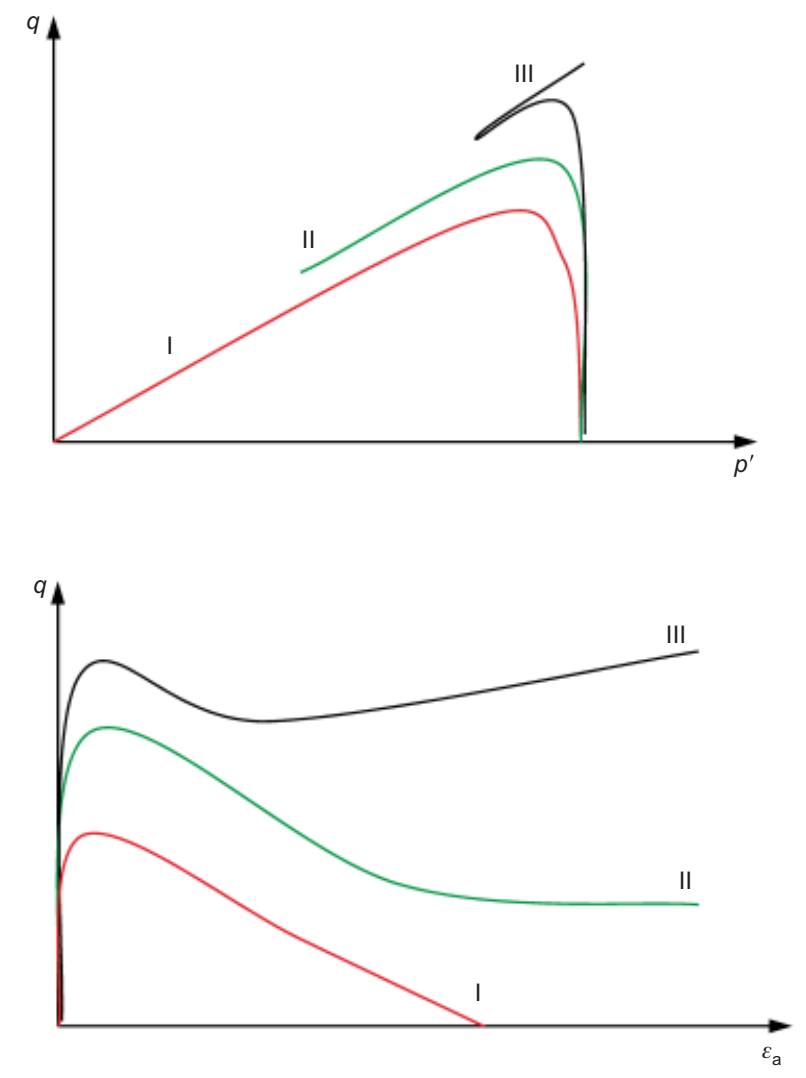

Fig. 1. Typical patterns of strain-softening response of loose sand of varying quantities. From a more fundamental point of view, the characteristics of both fine and coarse particles, such as shape, size and plasticity, can significantly affect the packing patterns and interactions of the particles, and hence their mechanical behaviour. Therefore it is essential to explore how particle characteristics play a role in the overall response of mixed soils. This paper reports a study that aimed to address the problem from this micromechanics viewpoint, focusing mainly on the role of particle shape in altering the undrained shearing behaviour of mixed soils.

The study consisted of an integrated experimental programme at both the macro scale and the micro (grain) scale, and incorporated several important considerations. First, non-plastic fines should be distinguished from plastic fines in exploring the role of particle shape. This is to rule out the large uncertainty associated with the chemical-physical effects of plasticity fines, and to ensure that the external forces are transmitted by direct interparticle contacts. Second, the shapes of both fine and coarse particles should be examined in a quantitative rather than a qualitative way, so that a better idea of the diverse patterns of response that are potentially associated with particle shape can be developed. More importantly, the quantification may allow, as will be shown later, the potential relations between the grain-scale characteristics and the macro-scale properties to be discovered.

\section{TEST MATERIALS: PARTICLE CHARACTERISTICS}

The experiments involved two types of fines with distinct particle shapes and two host sands, giving four binary mixtures. The microscope images of these materials are shown in Fig. 2. The two host sands were Toyoura sand (TS) and Fujian sand (FS), both being quartzitic and comprising angular to sub-rounded particles. The two types of fines were crushed silica and glass bead, both being non-plastic and having similar mineralogy. Glass beads were used as an analogue soil because of their similar mineralogy yet ideally rounded shape; with similar considerations several investigators have used coarse glass beads to study the influence of particle shape on the behaviour of sand (e.g. Santamarina \& Cho, 2001; Cavarretta et al., 2010). On the other hand, the crushed silica fines used in this study were much more angular, with irregular geometry. The grain-scale characteristics of these materials, including mean particle size, gradation, aspect ratio, flatness and roundness, were investigated carefully prior to performing triaxial tests on their mixtures.

\section{Particle size and gradation}

The particle size distribution curves of Toyoura and Fujian sands, determined by dry-sieving tests, are shown in Fig. 3. Both were uniformly graded, and had mean diameters of $216 \mu \mathrm{m}$ (Toyoura sand) and $397 \mu \mathrm{m}$ (Fujian sand). The grading curves of the two types of fines were determined by sedimentation tests, giving a mean size of $53.9 \mu \mathrm{m}$ for the crushed silica fines and $43.6 \mu \mathrm{m}$ for the glass beads. More details of the gradations of these materials are summarised in Table 1.

In addition to the conventional soil mechanics methods, the laser diffraction method was also used to determine the particle sizes and gradations of these materials. The results are also presented in Fig. 3 and included in Table 1 for the purpose of comparison. The principle of the laser diffraction method is that a particle passing through a laser beam will scatter the light at an angle and at an intensity that are related to its size and orientation, as schematically illustrated in Fig. 4. The laser diffraction method calculates particle size based on Fraunhofer theory (Endoh et al., 1998) and 


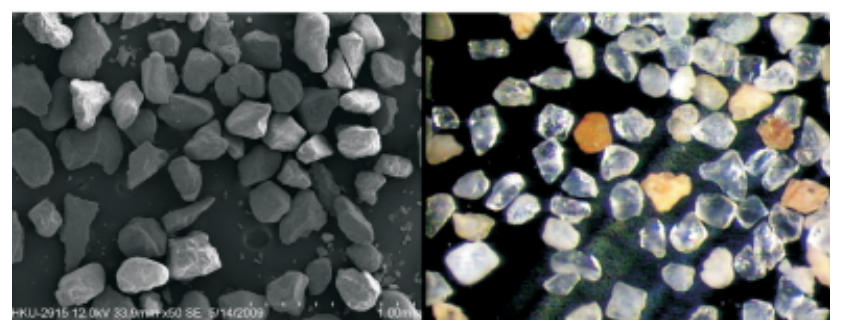

(a)

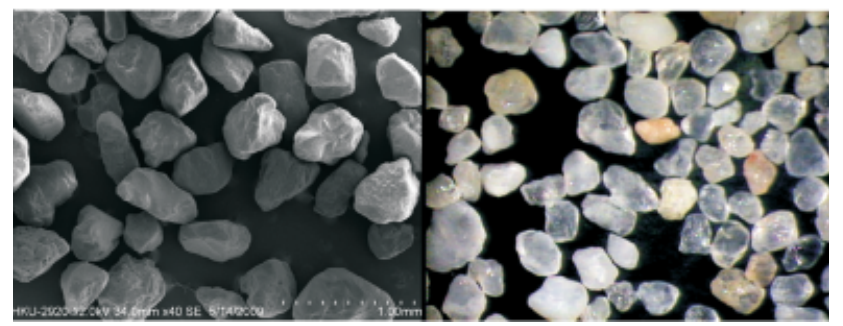

(b)

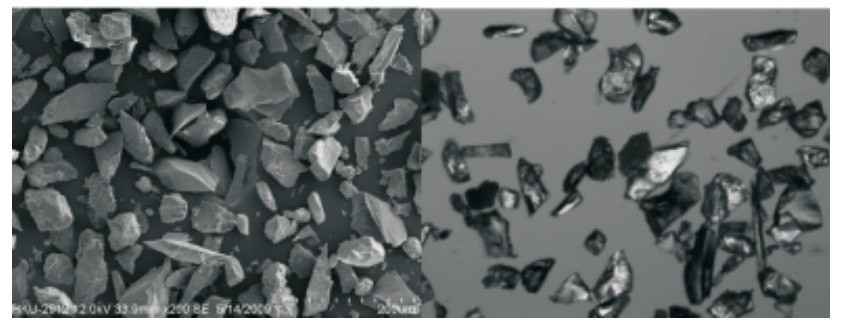

(c)

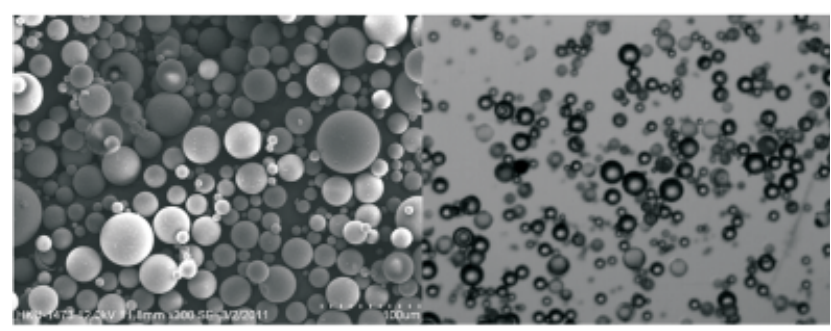

(d)

Fig. 2. Microscope images of test materials: (a) Toyoura sand; (b) Fujian sand; (c) crushed silica; (d) glass beads

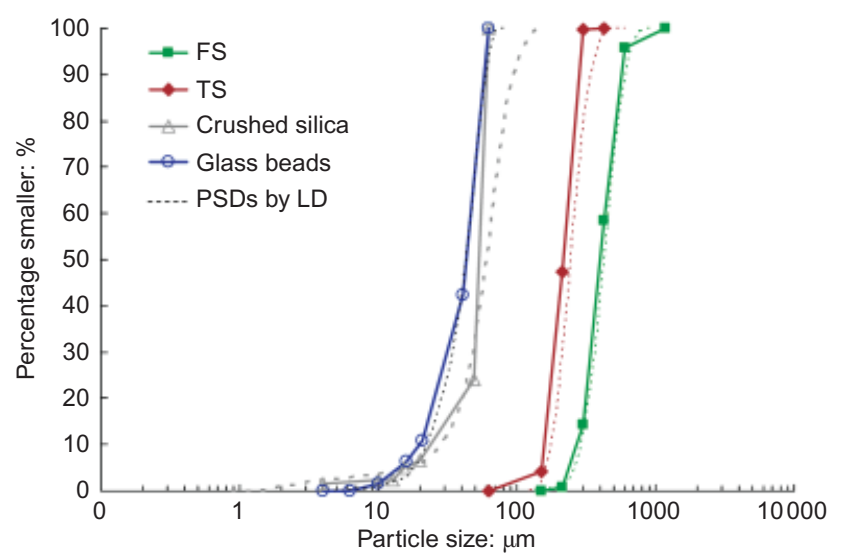

Fig. 3. Particle-size distribution curves of test materials

gives the diameter of an equivalent sphere exhibiting the same scattering pattern in the laser beam as the particle detected.

The data in Fig. 3 suggest that the measurements from the new technique and from the conventional soil mechanics methods are consistent in terms of mean particle size and gradation. Yet a discrepancy is also observed for each
Table 1. Physical properties of test materials

\begin{tabular}{|c|c|c|c|c|}
\hline & Fujian sand & Toyoura sand & $\begin{array}{l}\text { Crushed } \\
\text { silica }\end{array}$ & $\begin{array}{l}\text { Glass } \\
\text { beads }\end{array}$ \\
\hline $\begin{array}{l}G_{\mathrm{s}} \\
\text { Roundness } \\
\text { (RMSD }^{*} \text { ) } \\
\text { Particle size } \\
\text { distribution } \\
D_{10}: \mu \mathrm{m} \\
D_{50}: \mu \mathrm{m} \\
D_{60}: \mu \mathrm{m} \\
C_{\mathrm{u}} \\
\text { Particle size } \\
\text { distribution } \\
D_{10}: \mu \mathrm{m} \\
D_{50}: \mu \mathrm{m} \\
D_{60}: \mu \mathrm{m} \\
C_{\mathrm{u}}\end{array}$ & $\begin{array}{l}282 \cdot 0 \\
397 \cdot 0 \\
432 \cdot 0 \\
1 \cdot 532\end{array}$ & $\begin{array}{l}177 \cdot 3 \\
245 \cdot 9 \\
263 \cdot 1 \\
1 \cdot 484\end{array}$ & $\begin{array}{l}29 \cdot 4 \\
61 \cdot 1 \\
66 \cdot 9 \\
2 \cdot 278\end{array}$ & $\begin{array}{l}22 \cdot 5 \\
43 \cdot 4 \\
47 \cdot 2 \\
2 \cdot 096\end{array}$ \\
\hline
\end{tabular}

* Root mean square deviation of the overall roundness.

$\dagger$ By sieving or sedimentation.

By laser diffraction.

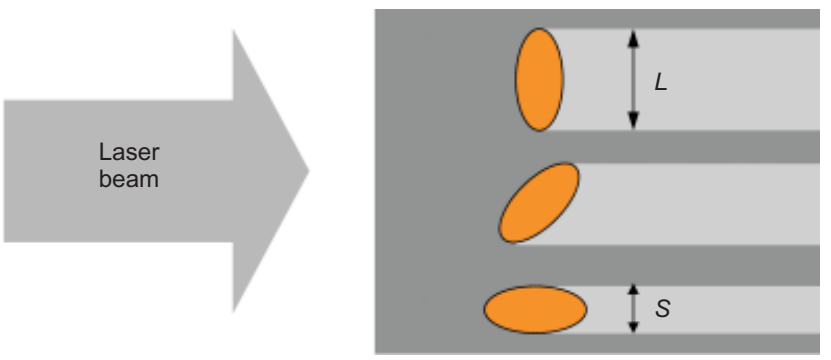

Fig. 4. Schematic illustration of laser diffraction method for particle analysis

material. It is interesting to note that the degree of discrepancy is largest for the crushed silica fines, whereas it is negligible for glass beads. This observation is understandable, given that the conventional and new sizing techniques involve different physical phenomena (Jennings \& Parslow, 1988; Endoh et al., 1998; Abbireddy et al., 2009). Generally, the more anisometric the particle is, the larger is the difference. As will be discussed later, this difference can be used to extract particle-shape information.

\section{Aspect ratio and flatness}

Figure 4 illustrates for an ellipsoid in the laser beam how its projected area varies with its orientation. The maximum and minimum projected areas are produced by the particle with its major axis $L$ and minor axis $S$ perpendicular to the laser beam respectively. For a particle being randomly oriented in the beam, the projected area, as well as the equivalent spherical diameter $D_{\mathrm{LD}}$, can be estimated as a function of the aspect ratio defined by Jennings \& Parslow (1988)

$$
r_{\mathrm{JP}}=\frac{L}{S}
$$

Similarly, there is a relation between the Stokes diameter $D_{\text {Stokes}}$, determined by the sedimentation technique, and the aspect ratio $r_{\mathrm{JP}}$, for randomly oriented oblate particles. By comparing the difference between $D_{\mathrm{LD}}$ and $D_{\text {Stokes, }}$, an equation to evaluate the aspect ratio is given by Jennings \& Parslow (1988) as 


$$
\frac{D_{\mathrm{Stokes}}}{D_{\mathrm{LD}}}=\left[\frac{2 r_{\mathrm{JP}} \arctan \sqrt{r_{\mathrm{JP}}^{2}-1}}{\left(r_{\mathrm{JP}} \sqrt{r_{\mathrm{JP}}^{2}-1}\right)+\ln \left(r_{\mathrm{JP}}+\sqrt{r_{\mathrm{JP}}^{2}-1}\right)}\right]^{1 / 2}
$$

Another shape parameter, termed particle flatness, can also be introduced from the measurements of $D_{\mathrm{LD}}$ and $D_{\text {Stokes }}$ as defined by Endoh et al. (1998)

$$
r_{\mathrm{E}}=\frac{D_{\mathrm{LD}}}{D_{\text {Stokes }}}
$$

The basis for equation (3) is that the ratio of projected area diameter and thickness measured from the scanning electron microscope photographs is similar to the ratio of median diameters determined by laser diffraction and by sedimentation (Endoh et al., 1998). A larger value of flatness indicates a less spherical shape of particle.

Both parameters were determined for the two types of fines, as given in Table 2. The aspect ratio and flatness of the glass beads were close to unity, implying a perfectly spherical shape, whereas the larger values for crushed silica fines indicate that their constituent particles were anisometric. Obviously, the derived shape information is consistent with that shown in the microscope images.

\section{Particle roundness}

Roundness is considered a key shape parameter here, because it describes the angularity of a particle. It can be determined as (Wadell, 1932)

$$
R=\frac{\sum\left(r_{\mathrm{i}} / N\right)}{r_{\max }}
$$

where $r_{\mathrm{i}}$ is the radius of the inscribed circle associated with a surface feature of the particle, $N$ is the number of features, and $r_{\max }$ is the radius of the largest circle that may be inscribed within the particle (see Fig. 5(a)). For each tested material, at least 40 grains with clear surface features were picked at random, and the calculated values were then averaged to give the overall roundness.

The values of overall roundness of the four materials are given in Table 1, and a graphical comparison is shown in Fig. 6. Generally, the variation of measured roundness was within a range similar to that reported in the literature (e.g. Rouse et al., 2008). Among the four materials used in the

Table 2. Form parameters of fines

\begin{tabular}{l|c|c}
\hline & Crushed silica & Glass beads \\
\hline Aspect ratio, $r_{\mathrm{JP}}$ & 2.597 & $\sim 1.000$ \\
Flatness, $r_{\mathrm{E}}$ & 1.133 & 0.995 \\
\hline
\end{tabular}

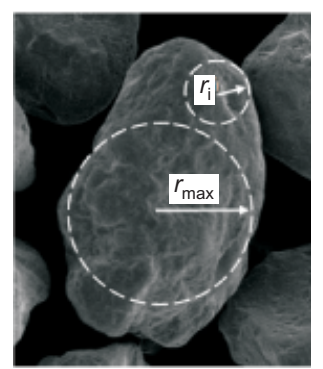

(a)

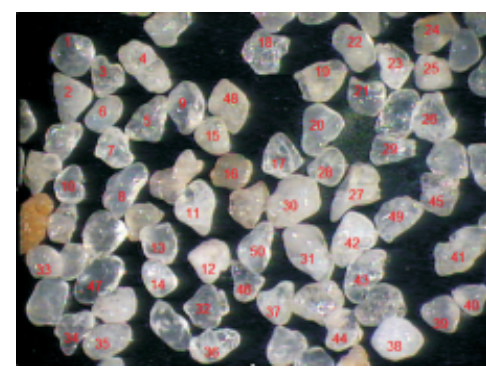

(b)
Fig. 5. Schematic illustration of particle roundness measurement

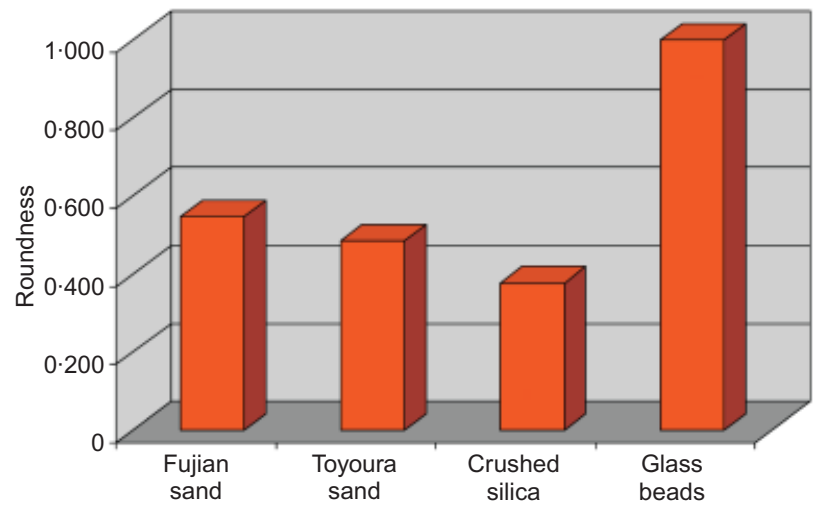

Fig. 6. Measured particle roundness of test materials

study the glass beads were most rounded, whereas the crushed silica fines were most angular, with the roundness being as low as $0 \cdot 377$. Of the two clean sands, although both showed a similar shape in their microscope images, Toyoura sand was determined to be more angular than Fujian sand.

\section{Variation of maximum void ratio with fines content}

The loosest stable packing of a granular soil reflects to some extent the influence of particle shape. It is thus of interest to examine how adding fines of distinct shapes into a host sand affects the packing of the mixtures. Fig. 7 shows the variation of maximum void ratio, $e_{\max }$, with fines content for four mixtures: Toyoura sand mixed with crushed silica fines (denoted TSS); Toyoura sand mixed with glass beads (denoted TG); Fujian sand mixed with crushed silica (denoted FSS); and Fujian sand mixed with glass beads (denoted FG). The values of $e_{\max }$ were determined according to the procedure specified by BS 1377: Part 4. Although the procedure is suggested for sands with small fines fractions, the application of this procedure was extended to mixed soils at higher fines content to achieve a consistent comparison. Generally, the variation of $e_{\max }$ with fines content in Fig. 7 exhibits a similar trend to published data on different mixed soils (e.g. Lade et al., 1998).

All the four mixtures show a trend that the maximum void ratio first decreases and then increases with increasing fines

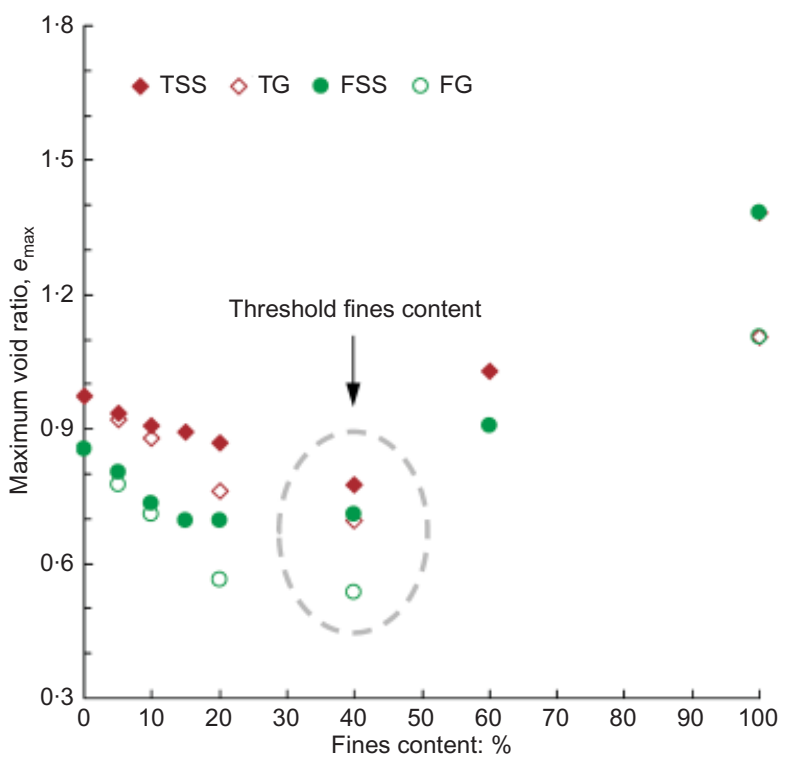

Fig. 7. Variation of maximum void ratio of mixed soils with fines content 
content. The fines content marking the transition appears to be around $40 \%$, which can be roughly regarded as the threshold fines content of the mixtures. The threshold value serves as an indicator for the nature of mixed soils varying from being sand-dominant to fines-dominant (Thevanayagam et al., 2002). In this study, focus has been placed on sanddominated mixtures, which are of interest in most practical problems. The observed variation of $e_{\max }$ is physically understandable: at a small fines content, fine particles tend to fill into the voids of the skeleton formed by the coarse sand particles, leading to a decrease in void ratio; this trend will continue until a minimum void ratio is reached at the threshold fines content, beyond which fine particles tend to separate the coarser particles apart, resulting in an increasing value of void ratio.

Of more interest here is how particle shape affects the attainable void ratio. First, two limiting cases in Fig. 7 are examined: zero fines content (i.e. the case of clean sand) and $100 \%$ fines content (i.e. the case of fines only). It is noted that the attainable $e_{\max }$ of Fujian sand $(0 \cdot 855)$ is less than that of Toyoura sand $(0 \cdot 974)$, whereas the value of $e_{\max }$ of the crushed silica (1.385) is markedly greater than that for glass beads $(1 \cdot 107)$. Given the difference in particle roundness of these materials, one may speculate that the maximum void ratio of an assembly of particles, at either the silt or sand size, tends to decrease with increasing particle roundness. This finding is supported by experimental observation on several coarse-grained soils (Miura et al., 1998).

Second, for a binary mixture of fine and coarse particles at fines content below the threshold value, Fig. 7 shows that adding glass beads, either to Toyoura sand or Fujian sand, tended to result in smaller values of $e_{\max }$ than adding crushed silica fines, and the deviation tended to become larger at higher fines content. A possible explanation for this observation is that the rounded glass beads were able to roll into the void spaces more efficiently than the angular grains of crushed silica; the underlying implication is that a mixed soil with rounded fines tends to be more susceptible to large volume change and, subsequently, to flow liquefaction. This important implication will be examined in more detail using undrained triaxial compression tests in the next section.

\section{UNDRAINED SHEAR BEHAVIOUR AT THE MACRO SCALE}

A series of undrained triaxial compression tests was performed on reconstituted specimens to investigate the shear response of the mixed soils. The systematic testing programme is summarised in Table 3 . For mixed soil specimens, the fines content is indicated in the parentheses; for example, $\operatorname{TSS}(5)$ stands for Toyoura sand mixed with $5 \%$ crushed silica fines, and FG(5) stands for Fujian sand mixed with $5 \%$ glass beads.

All specimens, each $71.1 \mathrm{~mm}$ in diameter and $142.2 \mathrm{~mm}$ high, were prepared by the moist tamping method with the under-compaction technique. This method was chosen because it is able to produce very loose samples, and has the advantage of preventing segregation. The same method has been successfully used in a large number of cyclic liquefaction tests on Fujian sand and Toyoura sand (Yang \& Sze, 2011a, 2011b). All specimens were saturated in two stages: initially by flushing the specimen with carbon dioxide and de-aired water, and then by applying back-pressure. Specimens with a $B$-value greater than 0.95 were considered saturated. After saturation, each specimen was isotropically consolidated to the target initial mean effective stress, from which undrained compression was started with a strain rate of $0.5 \% / \mathrm{min}$. The strain-controlled tests allowed detailed data collection for the post-peak response, thus giving a well-defined stress path and stress-strain curve.

The global void ratio of each specimen at the end of consolidation or prior to shearing was determined from the initial void ratio of the specimen during preparation and the volumetric strain that the specimen underwent during consolidation. Bearing in mind a potential error in determination of this post-consolidation void ratio for mixed soil specimens, a different method was also used to estimate the void ratio by measuring the final water content at the end of the test. Fig. 8 compares the values of the post-consolidation void ratio determined using the two methods for both clean sand specimens and mixed soil specimens, showing a reasonably good agreement.

\section{Behaviour of sand mixed with crushed silica fines}

Figure 9 shows the shear responses of the two host sands and their mixtures with $5 \%$ crushed silica in the $q-p^{\prime}$ and $q-\varepsilon_{\mathrm{a}}$ planes. Here $q$ is the deviatoric stress, $p^{\prime}$ is the mean effective stress, and $\varepsilon_{\mathrm{a}}$ is the axial strain. The initial mean effective stress for all the four tests here was $500 \mathrm{kPa}$, and the basis for comparison was the post-consolidation void ratio. The results indicate that the addition of crushed silica fines, either to Toyoura sand or to Fujian sand, always led to an increase in strain-softening as compared with the host sand on its own at a similar void ratio. For example, the Toyoura sand specimen at a void ratio of 0.867 exhibited a strongly dilative response, whereas the addition of $5 \%$ crushed silica fines resulted in a strain-softening response with a sudden reduction of strength at a strain level of $1.26 \%$.

The specimen of clean Fujian sand, although having a post-consolidation void ratio that was markedly lower than that of the specimen of clean Toyoura sand (0.816 compared with $0 \cdot 867)$, exhibited a very contractive response, with a dramatic strength loss at $0.88 \%$ strain followed by a rapid development of deformations up to $30 \%$. This discrepancy may serve as evidence for the impact of particle shape on the stress-strain behaviour of sand: the more rounded particles of Fujian sand tended to result in a less stable structure than the more angular particles of Toyoura sand. Furthermore, when $5 \%$ crushed silica fines were added to Fujian sand to form a mixed soil at a similar post-consolidation void ratio as the host sand, the degree of strain-softening was enhanced, leading to almost complete liquefaction (Fig. 9, specimen FSS).

It was also found that with an increasing quantity of crushed silica fines the mixed soil became more strainsoftening, leading to an increased reduction of shear strength, as shown in Fig. 10 for the case of Toyoura sand as the host sand.

\section{Behaviour of sand mixed with glass beads}

Of particular interest is the effect of the particle shape of the added fines. Fig. 11 shows how the behaviour of Toyoura sand was altered by the addition of fines of distinct shapes, with the test results for $\operatorname{TSS}(5)$ and $\mathrm{TG}(5)$ at the void ratio of about 0.868 compared in Figs 11(a) and 11(c), and the results for $\mathrm{TSS}(10)$ and $\mathrm{TG}(10)$ at the void ratio of about 0.844 compared in Figs 11(b) and 11(d). Evidently the addition of glass beads to Toyoura sand also resulted in an increase in strain-softening. However, compared with crushed silica fines, adding the same amount of glass beads appeared to result in a reduced strain-softening response.

In Fig. 12 the shearing responses of loose Fujian sand mixed with $5 \%$ crushed silica and with $5 \%$ glass beads are compared. A marked feature of Fig. 12 is that by adding glass beads into Fujian sand, the sand tended to become 
Table 3. Test series and key results

\begin{tabular}{|c|c|c|c|c|c|c|c|c|c|}
\hline \multirow[t]{2}{*}{ Test ID } & \multirow[t]{2}{*}{$e_{0}$} & \multirow[t]{2}{*}{$e$} & \multirow[t]{2}{*}{$p_{0}^{\prime}: \mathrm{kPa}$} & \multicolumn{2}{|c|}{ UIS } & \multicolumn{2}{|c|}{ QSS } & \multicolumn{2}{|c|}{ CS } \\
\hline & & & & $p^{\prime}: \mathrm{kPa}$ & $q: \mathrm{kPa}$ & $p^{\prime}: \mathrm{kPa}$ & $q: \mathrm{kPa}$ & $p^{\prime}: \mathrm{kPa}$ & $q: \mathrm{kPa}$ \\
\hline TS-IC01 & 0.969 & 0.942 & 500 & 374 & 343 & - & - & 51 & 66 \\
\hline TS-IC02 & $0 \cdot 940$ & 0.911 & 500 & 385 & 377 & 99 & 126 & 119 & 148 \\
\hline TS-IC03 & 0.925 & $0 \cdot 904$ & 500 & 383 & 463 & 307 & 413 & 395 & 503 \\
\hline TS-IC04 & $0 \cdot 911$ & $0 \cdot 894$ & 500 & - & - & - & - & 614 & 781 \\
\hline TS-IC05 & 0.903 & $0 \cdot 883$ & 500 & - & - & - & - & 649 & 808 \\
\hline TS-IC06 & 0.893 & 0.875 & 500 & - & - & - & - & 628 & 783 \\
\hline TS-IC07 & 0.886 & $0 \cdot 867$ & 500 & - & - & - & - & 745 & 925 \\
\hline TS-IC08 & $0 \cdot 872$ & $0 \cdot 856$ & 500 & - & - & - & - & 988 & 1236 \\
\hline TS-IC09 & 0.977 & 0.971 & 100 & 81 & 88 & - & - & 0 & 0 \\
\hline TS-IC10 & 0.958 & 0.952 & 100 & 93 & 121 & 56 & 81 & 94 & 126 \\
\hline TS-IC11 & $0 \cdot 940$ & 0.935 & 100 & 126 & 166 & 72 & 106 & 107 & 144 \\
\hline TS-IC12 & 0.935 & $0 \cdot 930$ & 100 & 183 & 244 & 170 & 232 & 238 & 304 \\
\hline TS-IC13 & $0 \cdot 921$ & 0.916 & 100 & - & - & - & - & 336 & 430 \\
\hline TS-IC14 & 0.903 & 0.898 & 100 & - & - & - & - & 448 & 566 \\
\hline TS-IC15 & $0 \cdot 877$ & 0.873 & 100 & - & - & - & - & 624 & 793 \\
\hline TS-IC16 & $0 \cdot 871$ & 0.866 & 100 & - & - & - & - & 669 & 844 \\
\hline TS-IC17 & $0 \cdot 865$ & $0 \cdot 861$ & 100 & - & - & - & - & - & - \\
\hline TSS(5)-IC01 & $0 \cdot 986$ & 0.939 & 500 & 334 & 259 & - & - & 0 & 0 \\
\hline TSS(5)-IC02 & 0.940 & 0.914 & 500 & 382 & 381 & 91 & 116 & 111 & 138 \\
\hline TSS(5)-IC03 & 0.914 & 0.890 & 500 & 384 & 419 & 163 & 214 & 183 & 229 \\
\hline TSS(5)-IC04 & 0.903 & 0.879 & 500 & 386 & 448 & 219 & 285 & 253 & 313 \\
\hline TSS(5)-IC05 & $0 \cdot 886$ & $0 \cdot 862$ & 500 & 410 & 485 & 303 & 398 & 368 & 457 \\
\hline TSS(5)-IC06 & $0 \cdot 865$ & $0 \cdot 848$ & 500 & - & - & - & - & 752 & 951 \\
\hline TSS(5)-IC07 & $0 \cdot 950$ & 0.941 & 100 & 87 & 98 & - & - & 0 & 0 \\
\hline TSS(5)-IC08 & $0 \cdot 940$ & 0.935 & 100 & 90 & 116 & - & - & 0 & 0 \\
\hline TSS(5)-IC09 & $0 \cdot 921$ & $0 \cdot 916$ & 100 & 128 & 171 & 84 & 118 & 116 & 155 \\
\hline TSS(5)-IC10 & $0 \cdot 903$ & 0.897 & 100 & 173 & 237 & 154 & 214 & 197 & 256 \\
\hline TSS(5)-IC11 & $0 \cdot 872$ & $0 \cdot 863$ & 100 & - & - & - & - & 274 & 335 \\
\hline TSS(5)-IC12 & $0 \cdot 865$ & $0 \cdot 860$ & 100 & - & - & - & - & 404 & 517 \\
\hline TSS(10)-IC01 & 0.903 & $0 \cdot 878$ & 500 & 352 & 378 & 84 & 116 & 91 & 122 \\
\hline TSS(10)-IC02 & $0 \cdot 865$ & $0 \cdot 844$ & 500 & 387 & 471 & 176 & 263 & 195 & 273 \\
\hline TSS(10)-IC03 & $0 \cdot 844$ & $0 \cdot 827$ & 500 & 429 & 576 & 359 & 499 & 388 & 504 \\
\hline TSS(10)-IC04 & $0 \cdot 828$ & $0 \cdot 810$ & 500 & - & - & - & - & 625 & 794 \\
\hline TSS(10)-IC05 & $0 \cdot 791$ & 0.774 & 500 & - & - & - & - & 931 & 1185 \\
\hline TSS(10)-IC06 & $0 \cdot 921$ & $0 \cdot 916$ & 100 & 112 & 147 & 13 & 24 & 16 & 28 \\
\hline TSS(10)-IC07 & $0 \cdot 903$ & 0.897 & 100 & 119 & 156 & 33 & 49 & 39 & 55 \\
\hline TSS(10)-IC08 & $0 \cdot 884$ & $0 \cdot 879$ & 100 & 157 & 216 & 102 & 146 & 129 & 172 \\
\hline TSS(10)-IC09 & $0 \cdot 872$ & $0 \cdot 867$ & 100 & 183 & 250 & 149 & 208 & 189 & 246 \\
\hline TSS(15)-IC01 & $0 \cdot 940$ & 0.900 & 500 & 345 & 288 & - & - & 0 & 0 \\
\hline TSS(15)-IC02 & $0 \cdot 865$ & $0 \cdot 842$ & 500 & 367 & 426 & - & - & 119 & 158 \\
\hline TSS(15)-IC03 & 0.828 & $0 \cdot 810$ & 500 & 412 & 552 & - & - & 333 & 434 \\
\hline TSS(15)-IC04 & $0 \cdot 791$ & $0 \cdot 775$ & 500 & - & - & - & - & 724 & 929 \\
\hline TSS(15)-IC05 & $0 \cdot 872$ & 0.867 & 100 & 137 & 181 & 52 & 68 & 61 & 78 \\
\hline TG(5)-IC01 & $0 \cdot 940$ & $0 \cdot 918$ & 500 & 410 & 372 & 47 & 52 & 64 & 71 \\
\hline TG(5)-IC02 & $0 \cdot 886$ & $0 \cdot 868$ & 500 & 535 & 579 & 444 & 515 & 605 & 698 \\
\hline TG(5)-IC03 & $0 \cdot 865$ & $0 \cdot 848$ & 500 & - & - & - & - & 944 & 1092 \\
\hline TG(5)-IC04 & $0 \cdot 940$ & 0.934 & 100 & 93 & 95 & - & - & 0 & 0 \\
\hline TG(5)-IC05 & $0 \cdot 903$ & 0.898 & 100 & 151 & 172 & 48 & 62 & 89 & 108 \\
\hline TG(5)-IC06 & $0 \cdot 865$ & $0 \cdot 860$ & 100 & - & - & - & - & 757 & 889 \\
\hline TG(10)-IC01 & $0 \cdot 940$ & 0.914 & 500 & 384 & 280 & - & - & 0 & 0 \\
\hline TG(10)-IC02 & $0 \cdot 888$ & $0 \cdot 866$ & 500 & 429 & 405 & 118 & 128 & 161 & 171 \\
\hline TG(10)-IC03 & $0 \cdot 865$ & 0.844 & 500 & 489 & 495 & 419 & 444 & 640 & 693 \\
\hline TG(10)-IC04 & $0 \cdot 828$ & $0 \cdot 812$ & 500 & - & - & - & - & 941 & 1059 \\
\hline TG(10)-IC05 & $0 \cdot 940$ & 0.935 & 100 & 89 & 75 & - & - & 0 & 0 \\
\hline TG(10)-IC06 & $0 \cdot 903$ & 0.898 & 100 & 143 & 151 & 34 & 45 & 88 & 101 \\
\hline TG(10)-IC07 & $0 \cdot 865$ & $0 \cdot 861$ & 100 & - & - & - & - & 563 & 610 \\
\hline FS-IC01 & 0.847 & 0.824 & 500 & 484 & 516 & 68 & 77 & 78 & 87 \\
\hline FS-IC02 & $0 \cdot 836$ & $0 \cdot 816$ & 500 & 473 & 546 & 183 & 235 & 219 & 270 \\
\hline FS-IC03 & $0 \cdot 824$ & $0 \cdot 803$ & 500 & 544 & 674 & 398 & 515 & 535 & 656 \\
\hline FS-IC04 & $0 \cdot 814$ & 0.794 & 500 & 590 & 736 & 520 & 666 & 681 & 828 \\
\hline FS-IC05 & $0 \cdot 802$ & $0 \cdot 782$ & 500 & - & - & - & - & - & - \\
\hline FS-IC06 & $0 \cdot 782$ & $0 \cdot 763$ & 500 & - & - & - & - & - & - \\
\hline FS-IC07 & 0.879 & $0 \cdot 871$ & 100 & 96 & 106 & - & - & 0 & 0 \\
\hline FS-IC08 & 0.856 & $0 \cdot 850$ & 100 & 123 & 152 & 9 & 18 & 28 & 41 \\
\hline FS-IC09 & 0.847 & 0.840 & 100 & 119 & 144 & 17 & 24 & 25 & 32 \\
\hline FS-IC10 & $0 \cdot 814$ & $0 \cdot 808$ & 100 & 214 & 284 & 186 & 251 & 294 & 373 \\
\hline FS-IC11 & $0 \cdot 789$ & $0 \cdot 783$ & 100 & - & - & - & - & 742 & 927 \\
\hline FSS(5)-IC01 & $0 \cdot 847$ & $0 \cdot 818$ & 500 & 389 & 360 & - & - & 38 & 41 \\
\hline
\end{tabular}


Table 3. (continued)

\begin{tabular}{|c|c|c|c|c|c|c|c|c|c|}
\hline \multirow[t]{2}{*}{ Test ID } & \multirow[t]{2}{*}{$e_{0}$} & \multirow[t]{2}{*}{$e$} & \multirow[t]{2}{*}{$p_{0}^{\prime}: \mathrm{kPa}$} & \multicolumn{2}{|c|}{ UIS } & \multicolumn{2}{|c|}{ QSS } & \multicolumn{2}{|c|}{$\mathrm{CS}$} \\
\hline & & & & $p^{\prime}: \mathrm{kPa}$ & $q: \mathrm{kPa}$ & $p^{\prime}: \mathrm{kPa}$ & $q: \mathrm{kPa}$ & $p^{\prime}: \mathrm{kPa}$ & $q: \mathrm{kPa}$ \\
\hline FSS(5)-IC02 & $0 \cdot 814$ & 0.790 & 500 & 405 & 428 & 115 & 148 & 136 & 170 \\
\hline FSS(5)-IC03 & $0 \cdot 802$ & 0.778 & 500 & 422 & 482 & 164 & 223 & 201 & 259 \\
\hline FSS(5)-IC04 & $0 \cdot 782$ & $0 \cdot 762$ & 500 & 461 & 573 & 316 & 418 & 387 & 487 \\
\hline FSS(5)-IC05 & $0 \cdot 754$ & 0.737 & 500 & - & - & - & - & 877 & 1102 \\
\hline FSS(5)-IC06 & $0 \cdot 717$ & $0 \cdot 701$ & 500 & - & - & - & - & - & - \\
\hline FSS(5)-IC07 & $0 \cdot 814$ & $0 \cdot 806$ & 100 & 97 & 119 & 22 & 26 & 29 & 35 \\
\hline FSS(5)-IC08 & 0.789 & $0 \cdot 781$ & 100 & 153 & 186 & 98 & 118 & 136 & 163 \\
\hline FSS(10)-IC01 & 0.782 & 0.758 & 500 & 368 & 389 & 51 & 73 & 62 & 86 \\
\hline FSS(10)-IC02 & $0 \cdot 754$ & 0.731 & 500 & 381 & 416 & 89 & 128 & 109 & 148 \\
\hline FSS(10)-IC03 & $0 \cdot 717$ & 0.699 & 500 & 454 & 594 & 294 & 408 & 379 & 492 \\
\hline FSS(10)-IC04 & 0.699 & $0 \cdot 680$ & 500 & 524 & 703 & 471 & 647 & 688 & 882 \\
\hline FSS(10)-IC05 & $0 \cdot 789$ & $0 \cdot 780$ & 100 & 112 & 127 & - & - & 9 & 7 \\
\hline FSS(10)-IC06 & $0 \cdot 814$ & $0 \cdot 805$ & 100 & 83 & 94 & - & - & 0 & 0 \\
\hline FG(5)-IC01 & $0 \cdot 782$ & $0 \cdot 761$ & 500 & 423 & 292 & - & - & 0 & 0 \\
\hline FG(5)-IC02 & 0.766 & 0.746 & 500 & 429 & 354 & 99 & 85 & 888 & 1002 \\
\hline FG(5)-IC03 & 0.749 & 0.726 & 500 & 415 & 305 & 102 & 83 & 1148 & 1316 \\
\hline FG(5)-IC04 & 0.753 & 0.734 & 500 & 382 & 373 & 179 & 145 & 1094 & 1269 \\
\hline FG(5)-IC05 & $0 \cdot 814$ & $0 \cdot 809$ & 100 & 80 & 73 & - & - & 0 & 0 \\
\hline FG(5)-IC06 & $0 \cdot 782$ & 0.775 & 100 & 117 & 107 & 40 & 27 & 564 & 611 \\
\hline FG(5)-IC07 & $0 \cdot 766$ & 0.759 & 100 & 138 & 125 & 42 & 30 & 521 & 556 \\
\hline
\end{tabular}

TS, Toyoura sand without fines; FS, Fujian sand without fines.

TSS, Toyoura sand with crushed silica; TG, Toyoura sand with glass beads.

FSS, Fujian sand with crushed silica; FG, Fujian sand with glass beads.

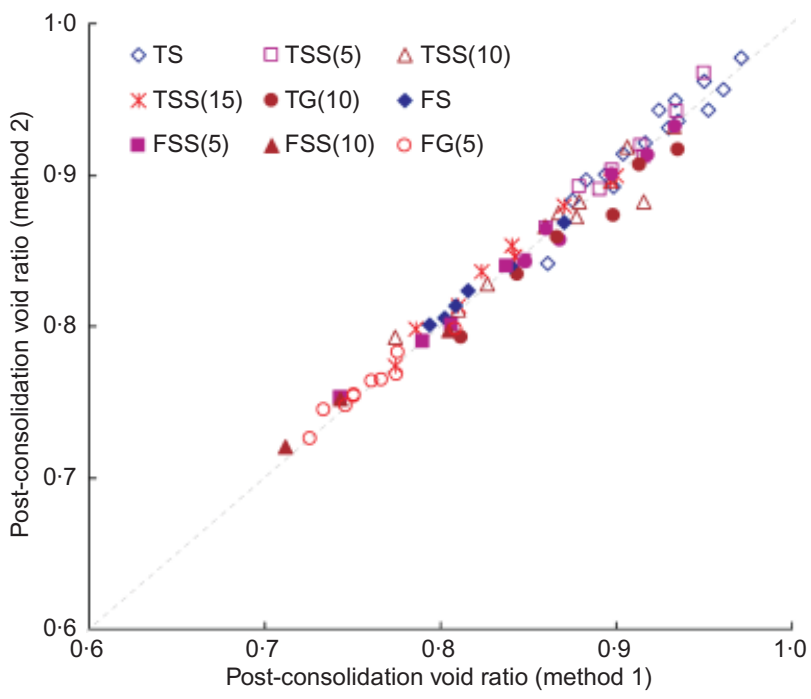

Fig. 8. Post-consolidation void ratios determined using various methods

more softening than by adding the angular crushed silica fines. This discrepancy, together with the observations on TSS and TG specimens, suggests that as well as the shape of fine particles, the shape of sand grains also plays an important role in the overall response of mixed soils; the two shape effects should be coupled. This significant finding is understandable, because a mixed soil can be approximately treated as a binary mixture of fine and coarse particles that, in loading, involves interactions through interparticle contacts that depend on the shapes of both the fine and coarse particles.

Furthermore, both FG specimens exhibited significant sawtooth fluctuations in the stress path and the stress-strain curve. For the looser specimen $(e=0.761)$, which liquefied completely, fluctuations were observed throughout the shearing process, whereas for the specimen at a relatively denser state $(e=0.734)$, fluctuations occurred in the initial stage of

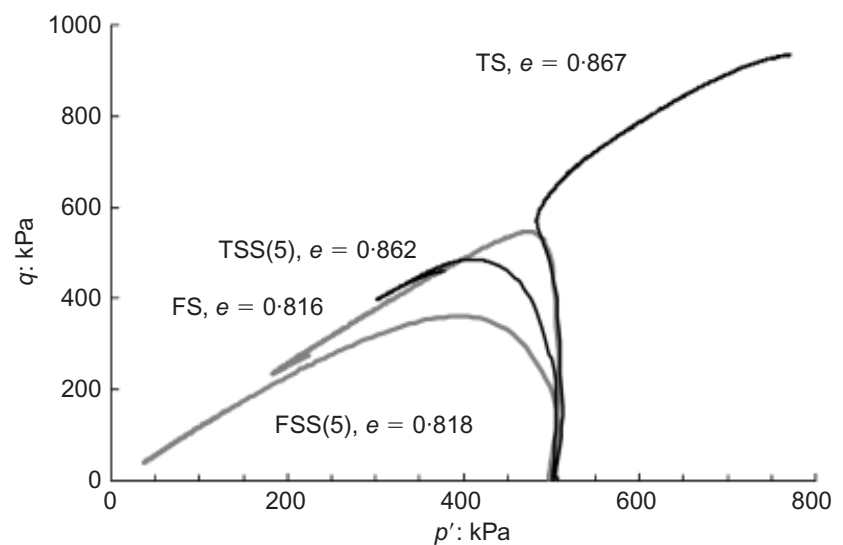

(a)

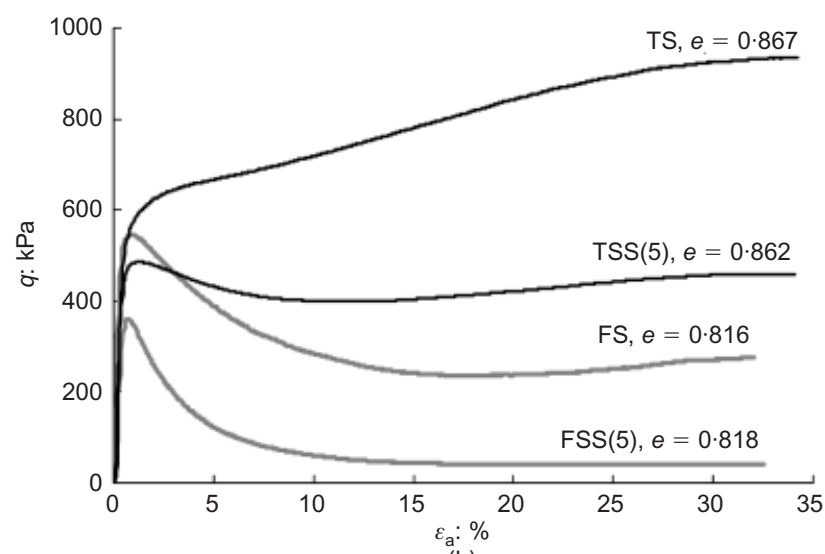

(b)

Fig. 9. Undrained shear behaviour of sands modified by addition of crushed silica fines: (a) stress path; (b) stress-strain relation

shearing only, and then vanished in the later stage of the test. It is striking that such fluctuation or stick-slip response was not observed in either shearing mixed soil FSS specimens or shearing specimens of TG and TSS. 


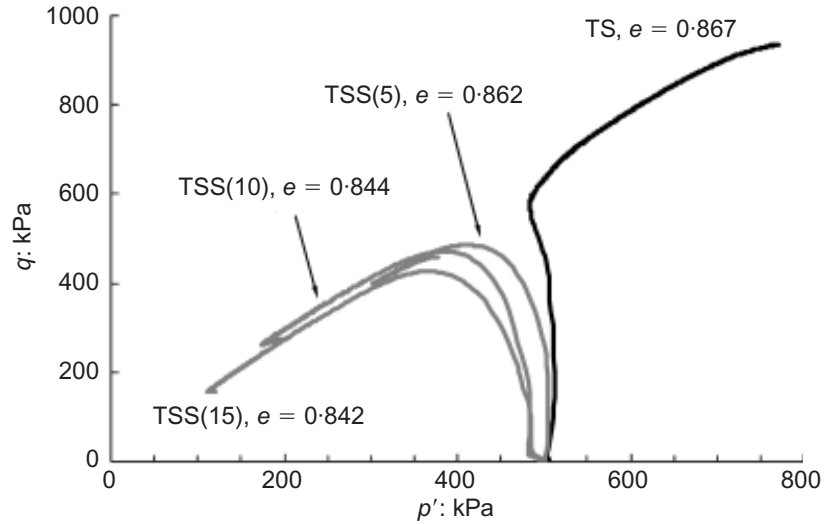

(a)

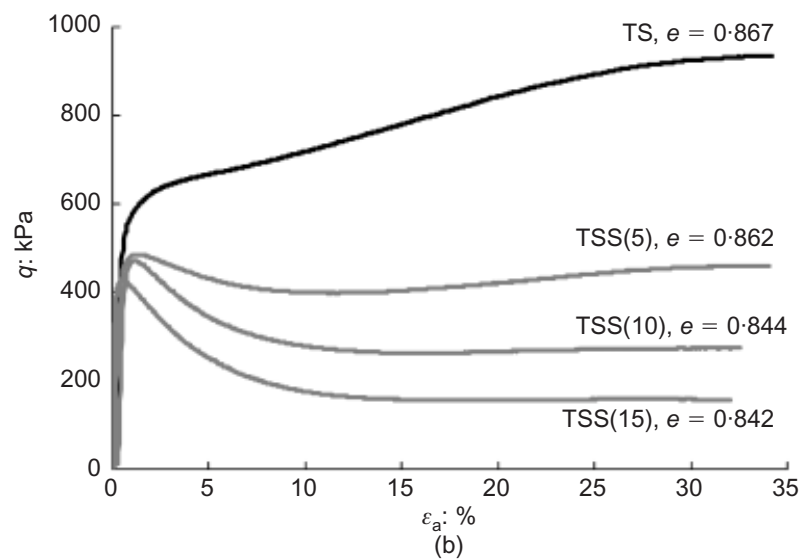

Fig. 10. Undrained shear behaviour of Toyoura sand modified by addition of crushed silica of varying quantities: (a) stress path; (b) stress-strain relation

The fluctuations observed on FG specimens are thought to be the result of rapid interactions between rounded glass beads and rounded coarse grains of Fujian sand during shearing. The interactions should involve losing and rebuilding of interparticle contacts that were frequent, leading to drastic fluctuations in stress that would not cease until a stable microstructure was established. This hypothesis appears to be well supported by the test on the relatively denser FG specimen $(e=0.734)$ in Fig. 12; the fluctuations indeed ceased when the specimen was sheared beyond a strain level of about $5 \%$. Note that at this strain level a local minimum strength was reached, and beyond that strain level a strain-hardening response occurred; evidently that was a transition state, known as the quasi-steady state (AlarconGuzman et al., 1988; Ishihara, 1993). The recent micromechanical analysis of Yang \& Dai (2011) has revealed that at the quasi-steady state the loss of contacts is most pronounced, and beyond the state the average number of contacts per particle will increase with strain; in this regard the quasi-steady state marks a change from a metastable to a stable microstructure.

\section{CSSM FRAMEWORK FOR MIXED SOIL}

The framework of critical state soil mechanics (CSSM) has been shown to be effective and useful for developing unified interpretations of monotonic and cyclic loading behaviour of sands under isotropic or anisotropic consolidation (Yang, 2002; Yang \& Sze, 2011a, 2011b). The central point of the CSSM framework is that there is an ultimate state of shear failure at which the sand deforms continuously under constant stress and constant volume (Schofield \& Wroth,
968: Jefferies \& Been, 2006). An attempt is made here to develop interpretations of the test results on the mixed soils in the CSSM framework, focusing mainly on the effects of particle shape on the critical state locus, the angle of shearing resistance at the critical state, the undrained instability or flow liquefaction line, and the degree of collapsibility.

Critical state locus in the $e-\log p^{\prime}$ plane

The critical state data for mixtures of Toyoura sand and crushed silica fines are plotted in the $e-\log p^{\prime}$ plane in Fig. 13(a), and the results for mixtures of Toyoura sand and glass beads are shown in Fig. 13(b). The curved shape of the critical state locus should not be attributed to particle breakage, because the stresses involved in this study were well below the stress level that might cause particle breakage of silica sand and glass beads (e.g. Verdugo \& Ishihara, 1996; Cavarretta et al., 2010). For both types of fines, the critical state locus was found to move down as the fines content was increased. This observation is consistent with that from previous experimental studies (Zlatovic \& Ishihara, 1995; Murthy et al., 2007). Of more interest here is the shape effect of fine particles: the rounded glass beads tended to result in the critical state locus lying at a higher position in comparison with the angular silica fines (Fig. 13(c)). Similar observations exist for the mixtures of Fujian sand and the two types of fines, as shown in Fig. 14.

The plots in Figs 13 and 14 were produced using the global void ratio, which has been widely used for describing the packing state of mixed soils. Recently an alternative variable, known as the equivalent skeleton void ratio, was suggested for analysis of the critical state locus in the $e-$ $\log p^{\prime}$ plane (Thevanayagam et al., 2002; Ni et al., 2004). The equivalent skeleton void ratio attempts to allow for fines content and the contribution of fines to interparticle contacts through a factor $b$. Although it is an interesting attempt, various issues, such as the range of $b$ values and the associated physical meaning, remain open to discussion. Therefore further analysis of the critical state data using the equivalent skeleton void ratio was not pursued in the present study.

\section{Critical state locus in the $q-p^{\prime}$ plane}

The critical state data for the mixed soils in the $q-p^{\prime}$ plane are shown in Fig. 15. Compared with the critical state locus in the $e-\log p^{\prime}$ plane, which shows a significant downward translation with increasing fines content, the critical state locus in the $q-p^{\prime}$ plane appears to be insensitive to the variation of fines content. It can be well represented by a straight line passing through the origin

$$
q=M_{\mathrm{cs}} p^{\prime}
$$

where $M_{\mathrm{cs}}$ is a constant relating to the so-called critical state friction angle as

$$
\sin \phi_{\mathrm{cs}}=\frac{3 M_{\mathrm{cs}}}{6+M_{\mathrm{cs}}}
$$

The critical state line for clean Toyoura sand (i.e. $0 \%$ fines content) is shown in Fig. 15(a), giving the critical state friction angle of $31.3^{\circ}$. Note that when the amount of crushed silica fines increases from $0 \%$ to $15 \%$, the friction angle only shows a slight increase $(\sim 2 \%$; see Table 4$)$. In comparison, the values of critical state friction angle for the mixtures of Fujian sand and crushed silica vary from $30.77^{\circ}$ at $0 \%$ fines content to $32^{\circ}$ at $10 \%$ fines content. The two plots in Fig. 15 indicate that the addition of glass beads to either Toyoura sand or Fujian sand, compared with the 


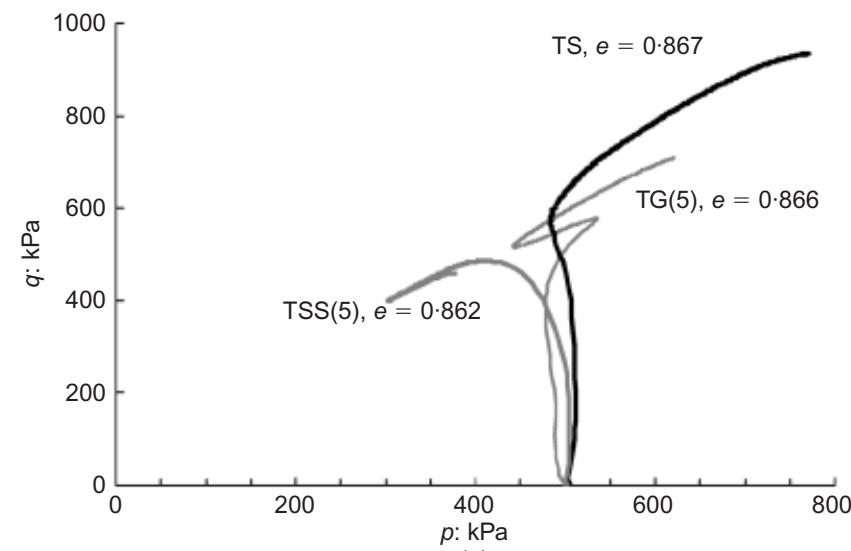

(a)

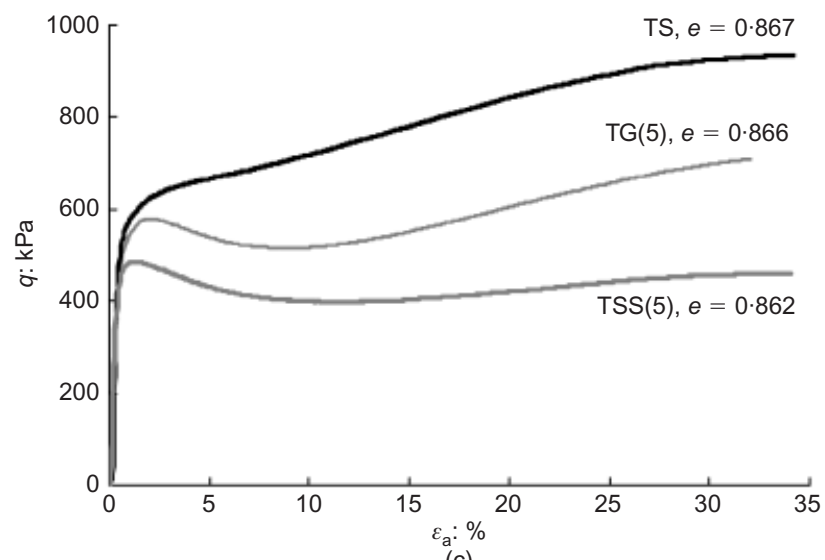

(c)

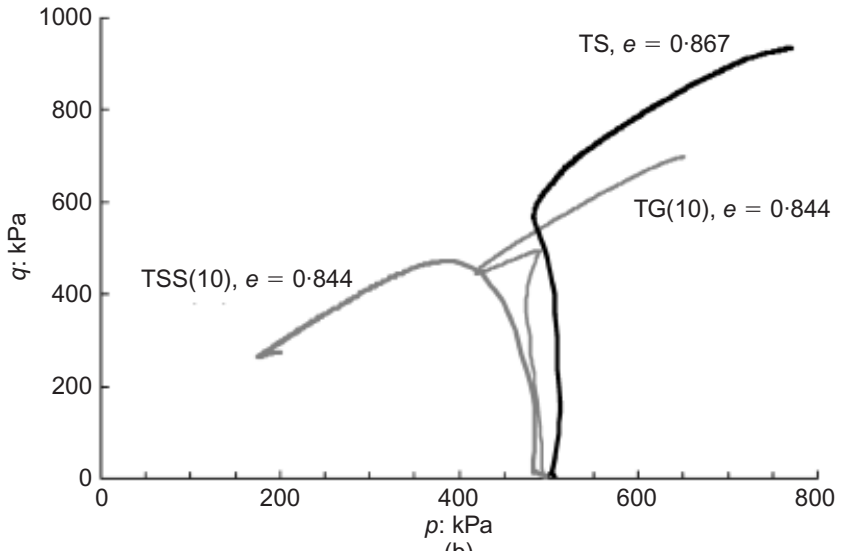

(b)

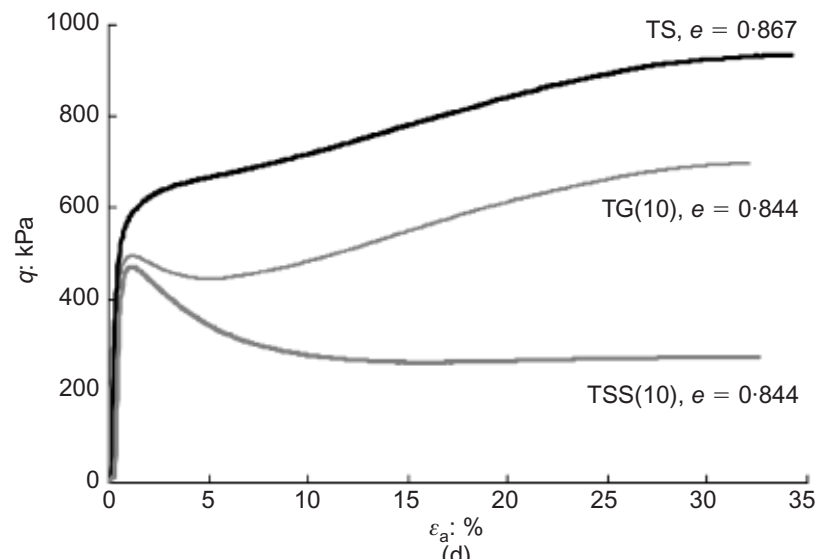

(d)

Fig. 11. Undrained shear behaviour of Toyoura sand modified by addition of fines of various shapes and quantities: (a), (b) stress path; (c), (d) stress-strain relation
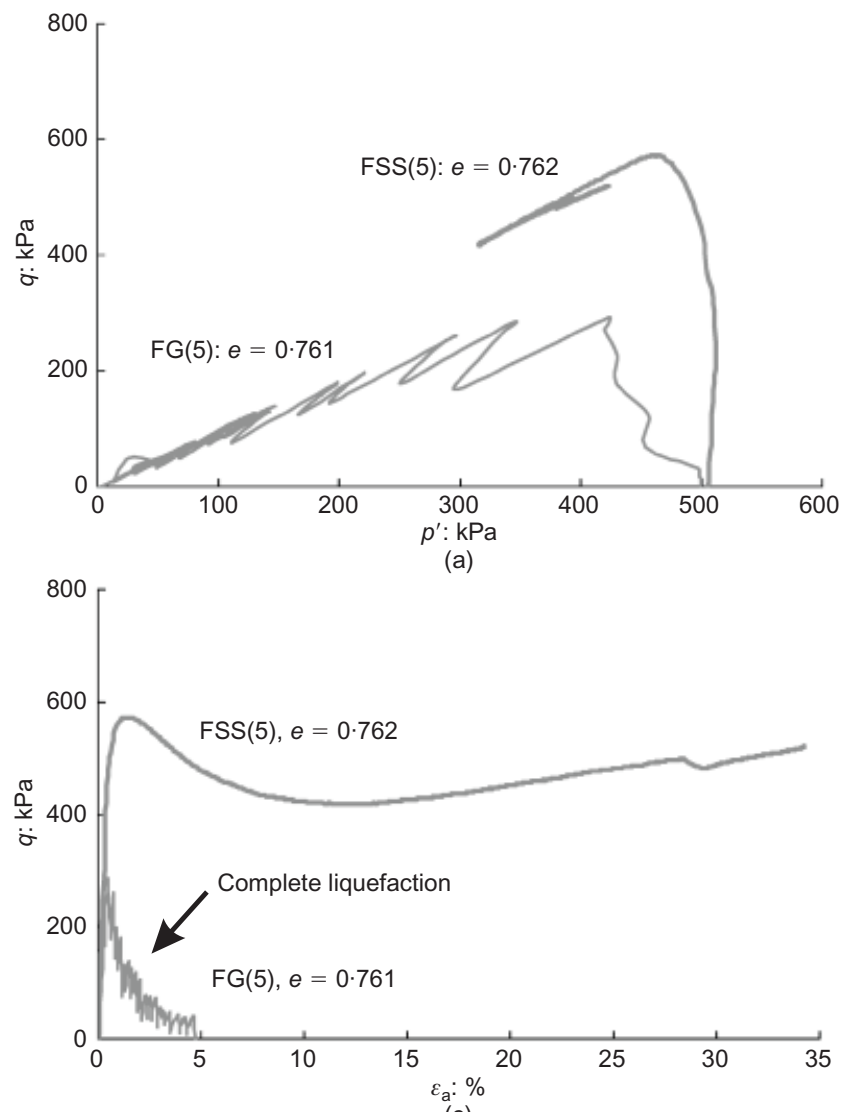

(c)

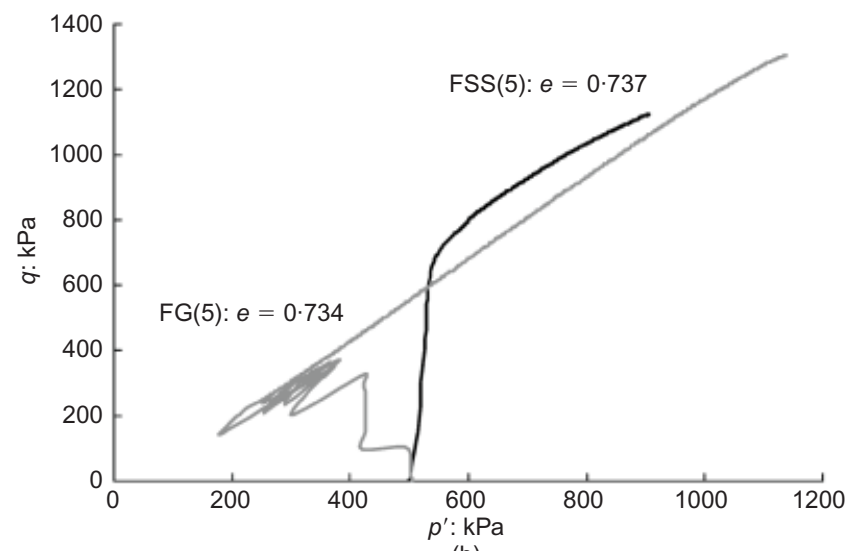

(b)

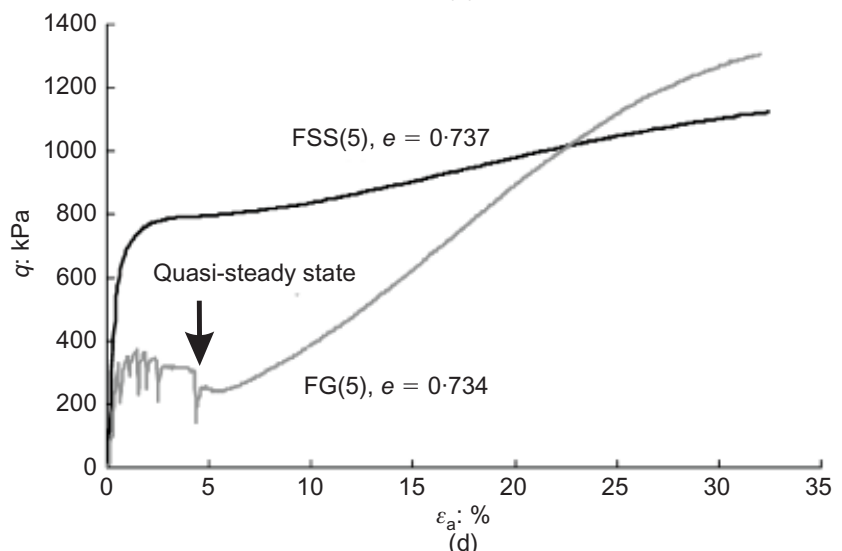

(d)

Fig. 12. Undrained shear behaviour of Fujian sand modified by addition of fines of various shapes and amounts: (a), (b) stress path; (c), (d) stress-strain relation 
1120

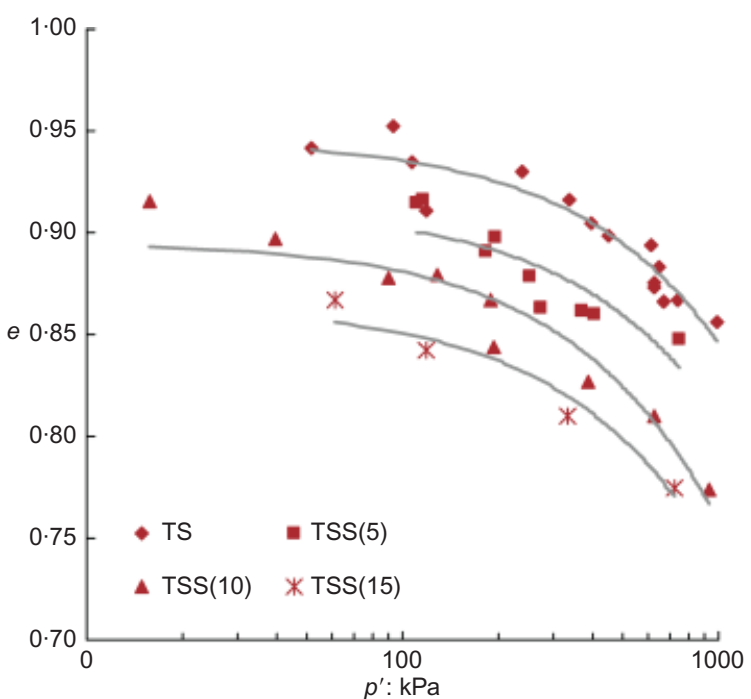

(a)

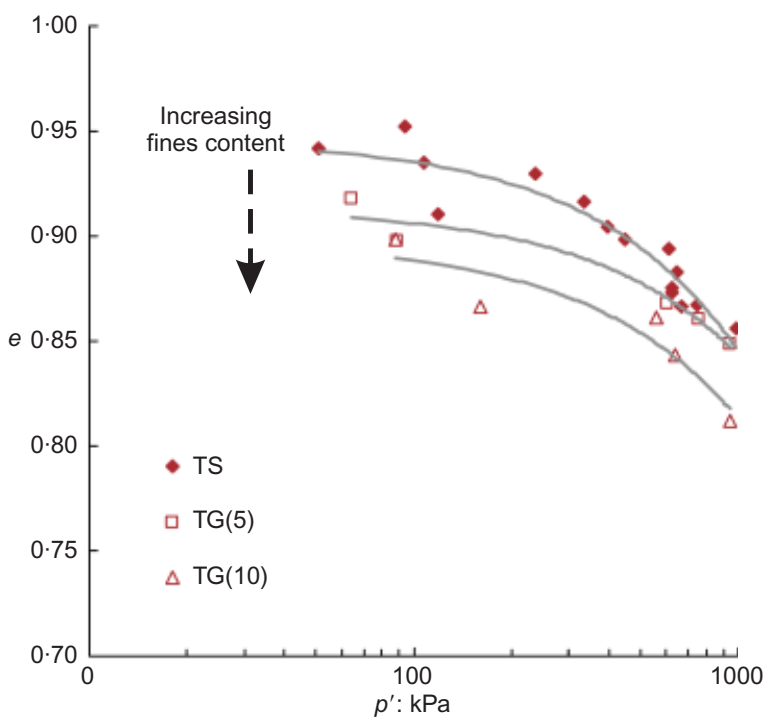

(b)

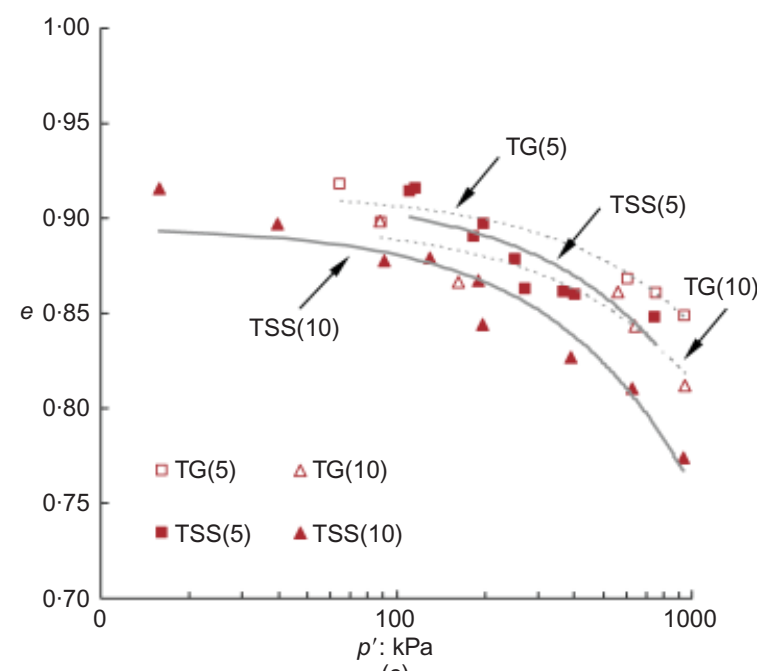

(c)

Fig. 13. Critical state loci of mixtures of Toyoura sand and fines in $e-\log p^{\prime}$ plane: (a) crushed silica as fines; (b) glass beads as fines; (c) comparison

addition of crushed silica fines, always resulted in an appreciable reduction of the critical state friction angle.

To identify the effect of particle shape better, the results in Table 4 are plotted in Fig. 16 in the form of critical state

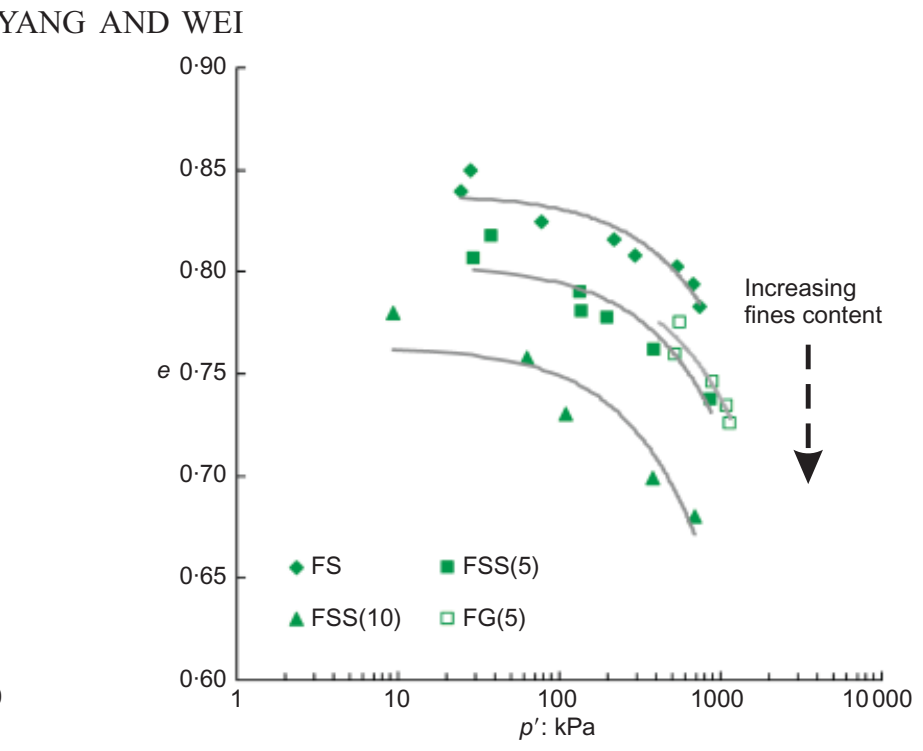

Fig. 14. Critical state loci of mixtures of Fujian sand and fines in $e-\log p^{\prime}$ plane

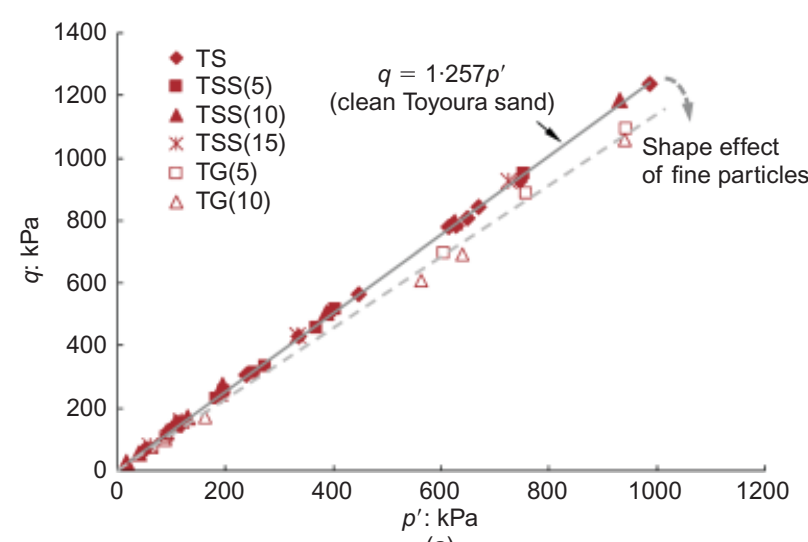

(a)

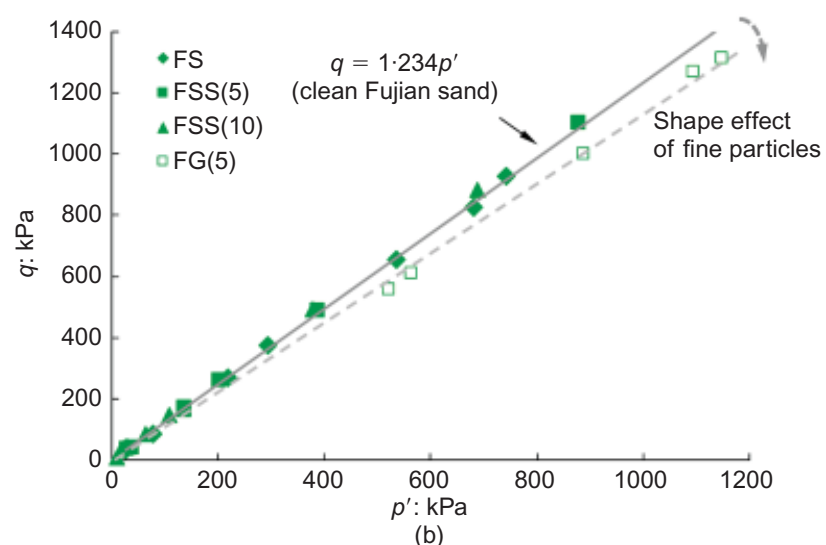

Fig. 15. Critical states in $q-p^{\prime}$ plane: (a) Toyoura sand as host sand; (b) Fujian sand as host sand

friction angle against fines content. There are several marked features. First, for zero fines content, the critical state friction angle tends to decrease as sand particles become more rounded (i.e. clean Toyoura sand compared with clean Fujian sand). This trend is in agreement with that observed by Cho et al. (2006) on various sands using simple tests to measure their angles of repose. Also, the data from this study and from that of Cho et al. (2006) indicate that no clear correlation exists between the critical state friction angle and the mean particle diameter for a range of particle 
Table 4. Effect of fines on critical state friction angle

\begin{tabular}{|c|c|c|c|c|c|}
\hline Test soil & $M_{\mathrm{cs}}$ & $\phi_{\mathrm{cs}}:$ degrees & Test soil & $M_{\mathrm{cs}}$ & $\phi_{\mathrm{cs}}$ : degrees \\
\hline TS & $1 \cdot 257$ & $31 \cdot 30$ & FS & $1 \cdot 234$ & $30 \cdot 77$ \\
\hline TSS(5) & 1.261 & $31 \cdot 40$ & FSS(5) & 1.256 & $31 \cdot 28$ \\
\hline $\operatorname{TSS}(10)$ & $1 \cdot 280$ & $31 \cdot 83$ & $\operatorname{FSS}(10)$ & $1 \cdot 287$ & $32 \cdot 00$ \\
\hline TSS(15) & $1 \cdot 287$ & 31.99 & - & - & - \\
\hline $\mathrm{TG}(5)$ & $1 \cdot 162$ & $29 \cdot 11$ & $\mathrm{FG}(5)$ & $1 \cdot 137$ & $28 \cdot 54$ \\
\hline TG(10) & $1 \cdot 106$ & $27 \cdot 83$ & - & - & \\
\hline
\end{tabular}

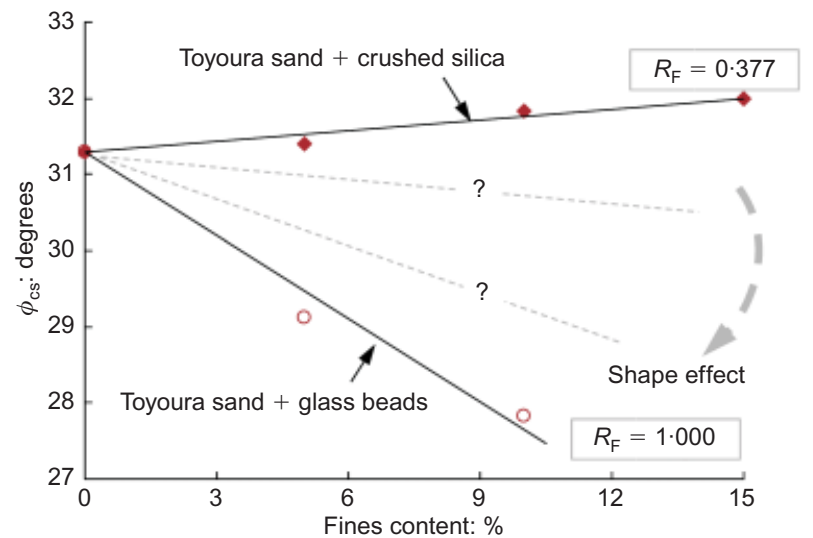

(a)

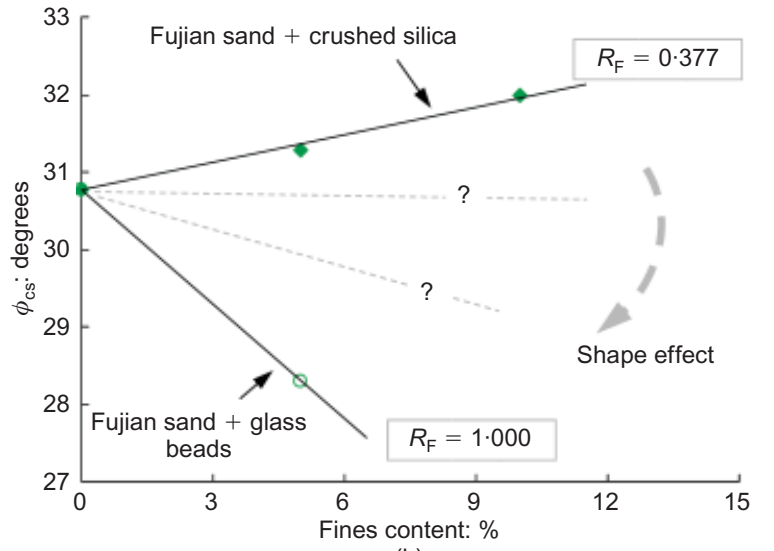

(b)

Fig. 16. Effects of particle shape and fines content on critical state friction angle: (a) Toyoura sand as host sand; (b) Fujian sand as host sand

size $(0.09-0.72 \mathrm{~mm})$, implying that the size effect may be minor. Second, for mixed soils with angular fines, the critical state friction angle tends to increase with increasing fines content, whereas for mixed soils with rounded fines, it tends to decrease with increasing fines content. And third, the variation of friction angle associated with rounded fine particles is markedly more significant than that in relation to angular fines.

In each plot of Fig. 16, given the two bounds established from the laboratory tests, two additional dashed lines were drawn to represent possible variations of the critical state friction angle with fines content for mixed soils containing fines of different roundness. Further verification of this speculation using experimental data should be of interest.

Furthermore, the variation with fines content of the critical state friction angle can be quantified for the four types of mixture (TSS, TG, FSS and FG) using the equations

TSS:

$$
\phi_{\mathrm{cs}}\left(F_{\mathrm{c}}\right)=0 \cdot 05 F_{\mathrm{c}}+\phi_{\mathrm{cs}}\left(F_{\mathrm{c}}=0\right)
$$

TG:

$$
\phi_{\mathrm{cs}}\left(F_{\mathrm{c}}\right)=-0 \cdot 36 F_{\mathrm{c}}+\phi_{\mathrm{cs}}\left(F_{\mathrm{c}}=0\right)
$$

FSS:

$$
\phi_{\mathrm{cs}}\left(F_{\mathrm{c}}\right)=0 \cdot 12 F_{\mathrm{c}}+\phi_{\mathrm{cs}}\left(F_{\mathrm{c}}=0\right)
$$

FG:

$$
\phi_{\mathrm{cs}}\left(F_{\mathrm{c}}\right)=-0.49 F_{\mathrm{c}}+\phi_{\mathrm{cs}}\left(F_{\mathrm{c}}=0\right)
$$

where $F_{\mathrm{c}}(\%)$ denotes fines content. The above four equations can also be written in the general form

$$
\phi_{\mathrm{cs}}\left(F_{\mathrm{c}}\right)=k F_{\mathrm{c}}+\phi_{\mathrm{cs}}\left(F_{\mathrm{c}}=0\right)
$$

in which $k$ is a parameter that indicates the rate of variation of the friction angle with fines content, and is dependent on particle characteristics.

To allow better for the coupling of the shape effect and the effect of fines content, a new index, referred to as combined roundness, is proposed, as

$$
R_{\mathrm{com}}=R_{\mathrm{HS}}\left(1-F_{\mathrm{c}}\right)+R_{\mathrm{F}} F_{\mathrm{c}}
$$

where $R_{\mathrm{HS}}$ and $R_{\mathrm{F}}$ denote the roundness of host sand and fines respectively. Given the measured values of roundness of the two types of fines, equation (12) predicts that the combined roundness of mixture $\mathrm{TG}$ or mixture $\mathrm{FG}$ will increase with an increasing quantity of glass beads, but the combined roundness of TSS or FSS will decrease with an increasing amount of crushed silica. The values of critical state friction angle (in degrees) are plotted against the combined roundness in Fig. 17, and a fairly good correlation is shown to exist between the two quantities

TSS and TG:

$\phi_{\mathrm{cs}}=-65 \cdot 2 R_{\mathrm{com}}+63$

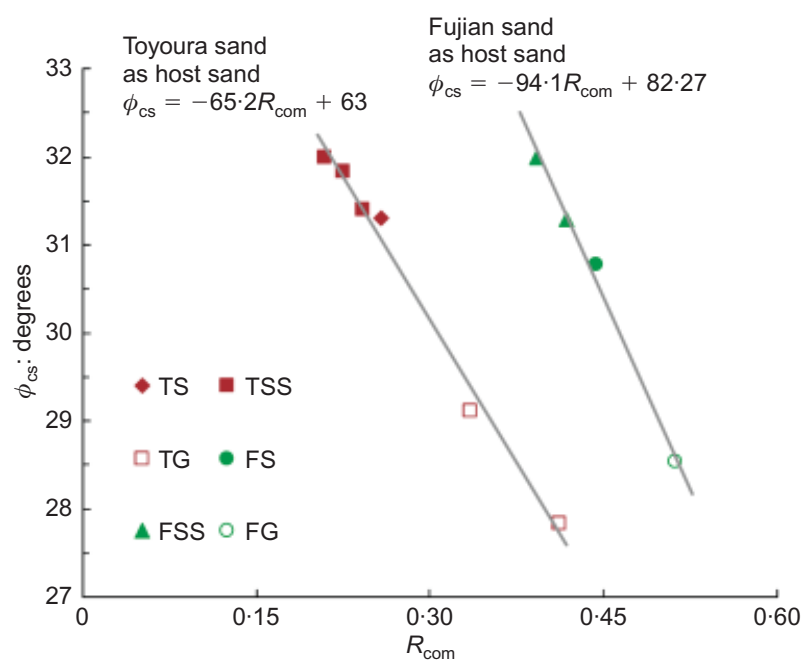

Fig. 17. Variation of critical state friction angle with combined roundness of mixed soils 
FSS and FG:

$$
\phi_{\mathrm{cs}}=-94 \cdot 1 R_{\mathrm{com}}+82 \cdot 27
$$

When either Toyoura sand or Fujian sand is the host sand, the critical state friction angle tends to decrease linearly with an increase in the combined roundness, $R_{\text {com }}$.

\section{Instability and collapsibility}

For a strain-softening response in $q-p^{\prime}$ space, the line passing through the origin and the peak point on the stress path (i.e. the undrained instability state, UIS) is defined as the critical stress ratio line, or flow liquefaction line (Vaid \& Chern, 1985; Yang, 2002). This line is useful in characterising the onset of instability or flow liquefaction. In the CSSM framework, Yang (2002) proposed that the flow liquefaction line of loose sand is not unique, but depends on the initial state of the sand in the form

$$
\left(\frac{q}{p^{\prime}}\right)_{\mathrm{UIS}}=\frac{M_{\mathrm{cs}}}{B} \exp (A \psi)
$$

where $\psi\left(=e-e_{\mathrm{cs}}\right)$ is the state parameter defined by Been \& Jefferies (1985), accounting for the difference between the current void ratio and the critical void ratio $\left(e_{\mathrm{cs}}\right)$ at the current mean effective stress; $M_{\mathrm{cs}}$ is the stress ratio at the critical state; and $A$ and $B$ are two calibrating parameters. If sand specimens are sheared from the same stress level, equation (15) can be given in the alternative form

$$
\left(\frac{q}{p^{\prime}}\right)_{\mathrm{UIS}}=\frac{M_{\mathrm{cs}}}{B \exp \left(A e_{\mathrm{cs}}\right)} \exp (A e)
$$

It is interesting to examine whether the relationship in equation (16), developed mainly from test data for clean loose sand, applies to mixed soils. To verify this, the values of the stress ratio at UIS for specimens sheared from $p_{0}^{\prime}=500 \mathrm{kPa}$ were determined, and they were plotted against the void ratio in Fig. 18. Apparently, equation (16) offers a reasonable prediction for the trend of data points for all mixed soils, except for specimens $\mathrm{FG}(5)$, primarily as a result of the difficulty in determining the instability state accurately from the fluctuant stress paths. For a given host sand, the $\left(q / p^{\prime}\right)_{\mathrm{UIS}}-e$ curves tend to shift to the left as the amount of fines increases, implying that the instability or flow liquefaction is triggered at a lower stress ratio for soils with higher fines content. Furthermore, given the same amount of fines, the shift appears to be more significant for the mixed soils containing rounded glass beads: that is, a sand mixed with rounded fines tends to form an even less stable structure than the same sand mixed with angular fines.

To quantify the strength loss for the strain-softening behaviour better, a parameter, termed the collapsibility index, is introduced, following the concept of Bishop (1967),

$$
I_{\mathrm{c}}=\frac{q_{\mathrm{UIS}}-q_{\mathrm{min}}}{q_{\mathrm{UIS}}}
$$

where $q_{\mathrm{UIS}}$ is the deviatoric stress at the UIS state, and $q_{\mathrm{min}}$ is the deviatoric stress at the quasi-steady state (QSS), or at the critical state when no QSS exists. Obviously this parameter characterises the degree of collapsibility, with its value varying from 1 , for complete liquefaction, to 0 , for a completely dilative response.

Figure 19 shows values of $I_{\mathrm{c}}$ for mixed soil specimens tested under $p_{0}^{\prime}=500 \mathrm{kPa}$. It appears that, for a given host sand and a given fines content, the variation of $I_{\mathrm{c}}$ with void ratio can be approximately characterised in three portions as

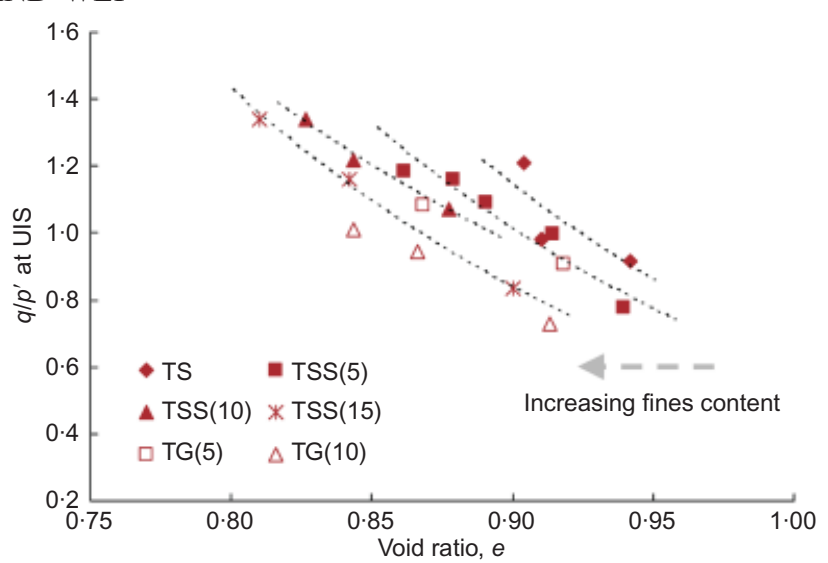

(a)

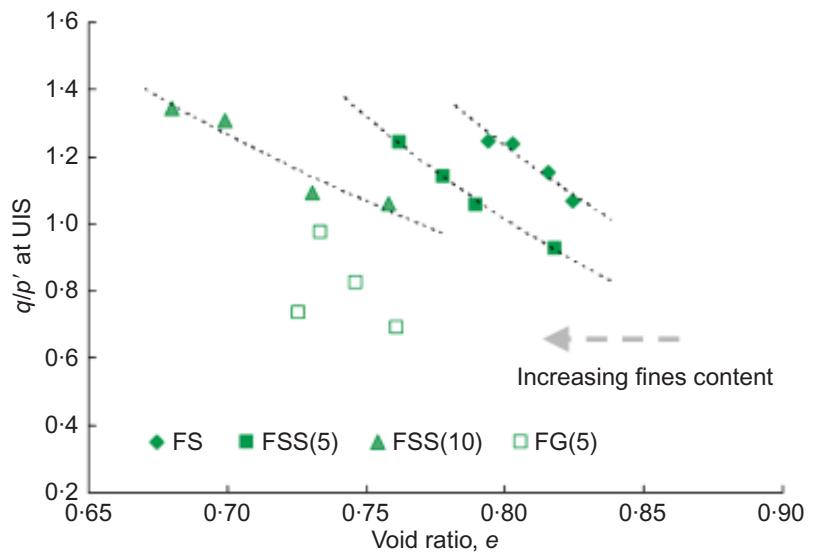

(b)

Fig. 18. Variation of stress ratio at undrained instability with void ratio: (a) mixtures with Toyoura sand as host sand; (b) mixtures with Fujian sand as host sand

$$
I_{\mathrm{c}}=\left\{\begin{array}{cc}
0 & e \leqslant e_{\mathrm{tg}} \\
\alpha e+\beta & e_{\mathrm{tg}}<e<e_{\mathrm{tm}} \\
1 & e \geqslant e_{\mathrm{tm}}
\end{array}\right.
$$

The first portion is for dense specimens with void ratio less than a critical value, showing no strength loss $\left(I_{\mathrm{c}}=0\right)$. This critical void ratio is referred to herein as the triggering void ratio, $e_{\mathrm{tg}}$; beyond this value strain-softening or strength loss will be triggered. The third portion is for very loose specimens with void ratio greater than a void ratio called the terminative void ratio, $e_{\mathrm{tm}}$, showing complete liquefaction without any residual strength (i.e. $I_{\mathrm{c}}=1$ ). For specimens in a medium dense to loose state with void ratio between $e_{\mathrm{tg}}$ and $e_{\mathrm{tm}}$, the degree of collapsibility or strain-softening increases with the void ratio in an approximately linear manner. The two parameters $\alpha$ and $\beta$ in equation (18) can be calibrated from test data.

The results in Fig. 19 suggest that the triggering void ratio depends on the fines content as well as on the nature of the host sand, but it does not appear to be sensitive to the shape of fine particles. This feature can be viewed better in Fig. 20 (a), which shows the variation of $e_{\mathrm{tg}}$ with fines content, where the $e_{\mathrm{tg}}$ values were determined from the trend lines in Fig. 19. Under the specific confining pressure, the void ratio for triggering strength loss for clean Toyoura sand was about 0.889; for the more rounded Fujian sand, the void ratio to trigger the strength loss was markedly lower, at about 0.787 . The two plots in Fig. 20 also suggest that strain-softening is triggered at a lower void ratio as the fines content increases, and that the presence of fines tends to result in a larger 


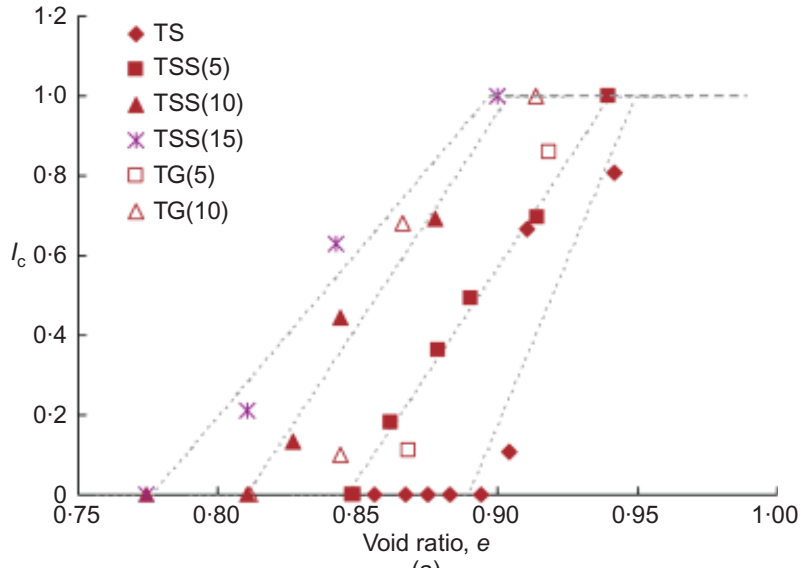

(a)

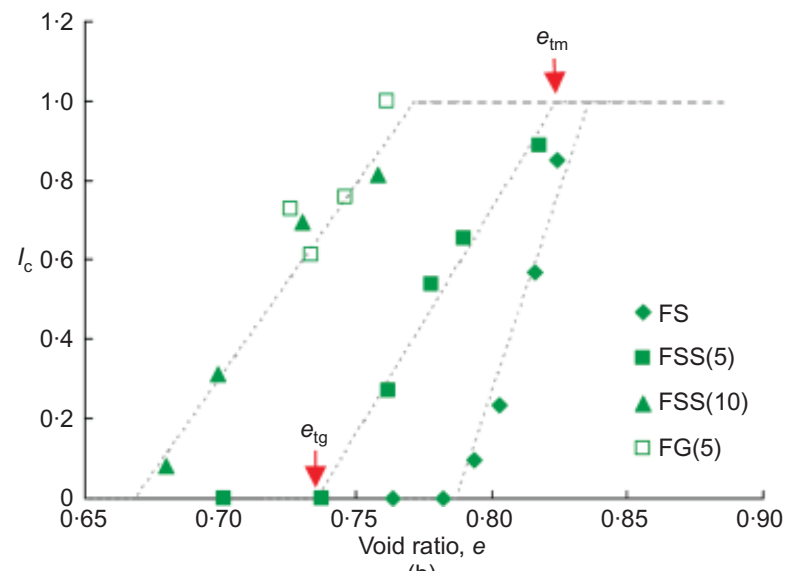

(b)

Fig. 19. Variation of collapsibility with void ratio: (a) mixtures with Toyoura sand as host sand; (b) mixtures with Fujian sand as host sand

range of void ratio for mixed soils, to go from a completely dilative response to complete liquefaction.

\section{GRAIN-SCALE CONCEPTUAL MODELS}

To explain the diverse patterns of overall response associated with particle shape, conceptual models at the grain scale are proposed, as illustrated in Fig. 21. There are four types of model, representing four typical interparticle contact mechanisms and movements in a binary mixture. Type I describes the contact and movement of a rounded fine particle with respect to a rounded coarse particle. Type II describes the contact and movement of a rounded fine particle with respect to an angular coarse particle. Similarly, Type III is for an angular fine particle in contact with a rounded coarse particle, and Type IV is for an angular fine particle in contact with an angular coarse particle.

In each conceptual model the two equal sides of the triangle simulate the path of the fine particle moving along the surface features of the coarse particle: as the base angle of the triangle becomes larger, the coarse particle becomes more angular, and thereby more work is required for the fine particle to move along the path to yield particle rearrangement. This explains why TSS specimens in loading appear to be more stable and stronger than FSS specimens, although both contain the same amount of crushed silica fines (Fig. 9).

Compared with the Type I model, the coarse particle in the Type III model shares a similar, rounded shape but the fine particle is more angular. This means that, in loading, the fine particle needs more effort to move along the path, because its angular shape does not favour rolling but rather

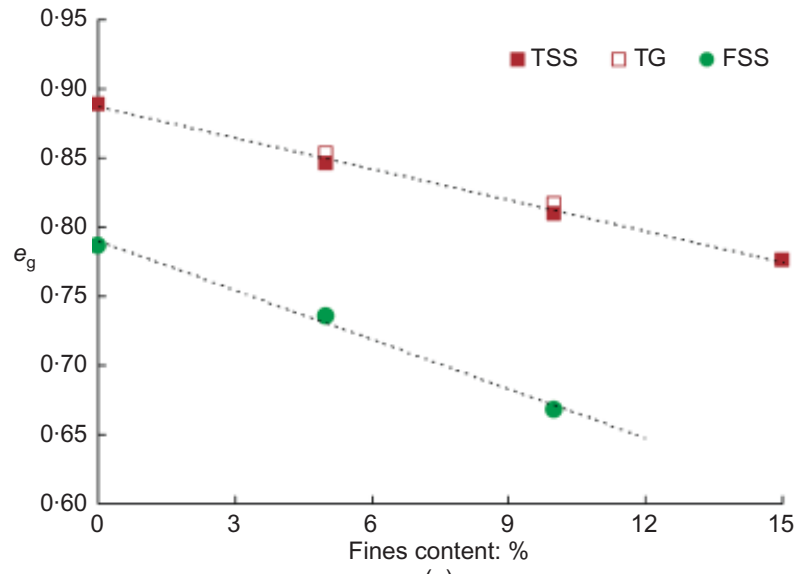

(a)

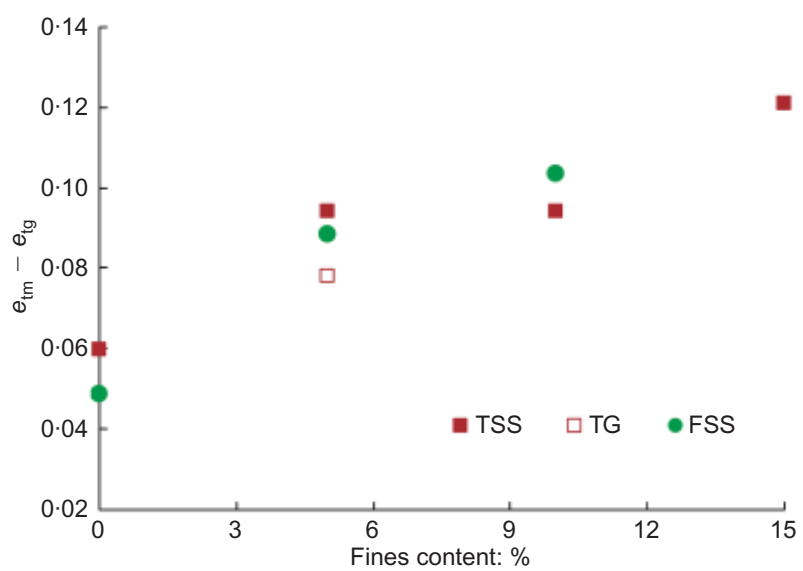

(b)

Fig. 20. Variation of (a) $e_{\mathrm{tg}}$ and (b) $\left(e_{\mathrm{tm}}-e_{\mathrm{tg}}\right)$ with fines content

favours sliding. Among the four models, Type IV represents the case in which particles are the most difficult to move and rearrange (i.e. the case of the most stable structure), whereas Type I represents the case in which particle movement and fabric change are the easiest to trigger (i.e. the most unstable structure). This explains why drastic fluctuations occurred in the FG specimens but no fluctuations took place in the FSS specimens (Fig. 12); it also explains why the TSS specimens showed the strongest resistance to the onset of instability or strain-softening compared with other mixed soils (Fig. 18).

\section{SUMMARY AND CONCLUSIONS}

This paper presents a systematic experimental study at the grain scale and the macro scale to examine the role of particle shape in the undrained shear behaviour of mixed soils. The study involved two types of non-plastic fines with distinct shapes, and two uniformly graded quartz sands. The major results and findings of the study are summarised as follows.

(a) The addition of crushed silica fines, either to Toyoura sand or to Fujian sand, resulted in an increase in strainsoftening, with the degree of softening increasing as higher percentages of fines were added. Adding silica fines to Fujian sand tended to produce an even less stable structure than adding the same amount of fines to Toyoura sand. The difference in particle shape of the two host sands can be a reason for the discrepancy in the macro-scale behaviour.

(b) Adding glass beads to Toyoura sand resulted in the mixed soil being less strain-softening in comparison with the 


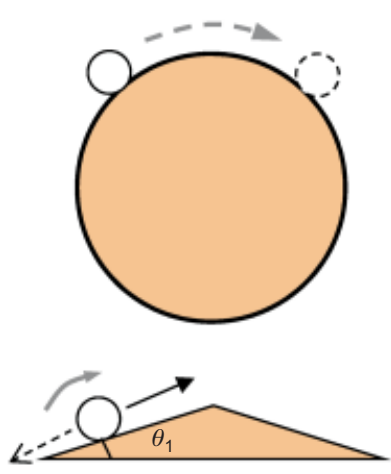

(a)
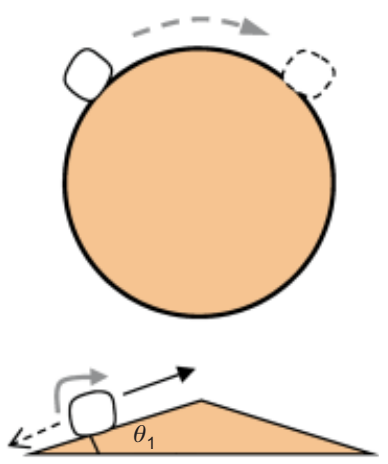

(c)
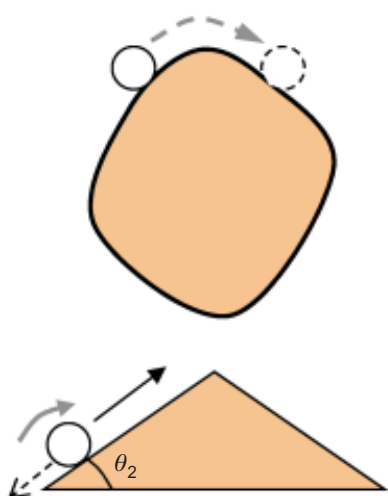

(b)
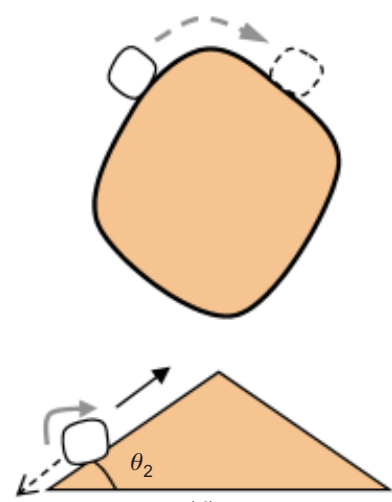

(d)
Fig. 21. Conceptual models explaining particle shape effects in mixed soils: (a) Type I, round-to-round; (b) Type II, round-toangular; (c) Type III, angular-to-round; (d) Type IV, angular-toangular

mixed soil formed by adding the same amount of crushed silica fines to the sand. On the other hand, the addition of glass beads to Fujian sand resulted in the mixed soil being significantly more softening than the mixture of Fujian sand and angular crushed silica fines. This finding indicates the important role of both fine and coarse particles in the deformation behaviour of mixed soils.

(c) For a clean sand without fines, the critical state friction angle tends to decrease with increasing roundness of sand particles, as manifested by the data for Fujian sand and Toyoura sand. When fines of rounded shape, such as glass beads, are added to the clean sand, the critical state friction angle of the mixture tends to decrease with an increase in fines content. However, when fines of angular shape, such as crushed silica, are present, the critical state friction angle tends to increase with fines content.

(d) The rate of variation of the critical state friction angle with fines content appears to be most significant for the mixture composed of coarse and fine particles that are both rounded, whereas it may be least significant for the mixture whose coarse and fine particles are both angular. A fairly good correlation exists between the critical state friction angle and the combined roundness, accounting for the roundness of constituent particles and fines content. As the combined roundness increases owing to an increased amount of rounded fines, the critical state friction angle decreases.

(e) The flow liquefaction line, characterising the onset of strain-softening or collapse in the stress space, is also state dependent for mixed soils. Given a specific type of fines, flow liquefaction can be triggered more easily for the mixed soil at higher fines content; with the same percentages of fines, a mixed soil containing rounded fines tends to exhibit higher susceptibility to flow liquefaction than a mixed soil containing angular fines.

( $f$ ) The conceptual models describing intergranular contacts and movements in a binary mixture provide a useful framework for explaining the variation in the overall material response. The round-to-round model represents the most unstable structures, where rounded fine particles favour rolling, as manifested by the drastic fluctuations in the stress-strain behaviour of the FG specimens. The angular-to-angular model represents the most stable structures, where angular particles favour sliding rather than rolling.

(g) The undrained shear response of the mixtures of Fujian sand and glass beads, characterised by drastic fluctuations in shear stress in the initial stage of shearing but no occurrence of such fluctuations in the later stage of shearing, provides strong evidence for the notion that the quasi-steady state marks a change from a metastable to a stable microstructure.

\section{ACKNOWLEDGEMENTS}

Financial support for the work presented in this paper was provided by the University of Hong Kong through the Seed Funding for Basic Research scheme (10400889). The work was also partially supported by the Outstanding Young Researcher Award scheme of the University of Hong Kong. The authors wish to thank Dr X. Y. Li of the University of Hong Kong for offering the Beckman Coulter LS for the PSD analysis in the study.

\section{NOTATION}

$A, B$ calibrating parameters in the relationship between $\left(q / p^{\prime}\right)_{\text {UIS }}$ and $\psi$ (or $e$ )

$b$ factor denoting fraction of fines contributing to interparticle contacts

$C_{\mathrm{u}} \quad$ coefficient of uniformity

$D_{10}$ grain size at which $10 \%$ of sample is finer

$D_{50}$ mean particle size

$D_{60}$ grain size at which $60 \%$ of sample is finer

$D_{\mathrm{LD}}$ equivalent spherical diameter determined by laser diffraction

$D_{\text {Stokes }}$ Stokes diameter determined by sedimentation

$e$ void ratio after consolidation

$e_{\mathrm{cs}}$ critical void ratio

$e_{\max }$ maximum void ratio of soil

$e_{\mathrm{tg}}$ triggering void ratio for characterising collapsibility

$e_{\mathrm{tm}}$ terminative void ratio for characterising collapsibility

$e_{0} \quad$ initial void ratio during preparation

$F_{\mathrm{c}}$ fines content

$G_{\mathrm{s}} \quad$ specific gravity

$I_{\mathrm{c}}$ collapsibility index

$k$ parameter indicating rate of variation of $\phi_{\mathrm{cs}}$ with $F_{\mathrm{c}}$

$L$ minor axis of particle

$M_{\mathrm{cs}}$ effective stress ratio at critical state

$N$ number of features examined for calculating roundness

$p^{\prime}$ mean effective stress

$p_{0}^{\prime} \quad$ initial mean effective stress (i.e. effective consolidation pressure)

$q$ deviatoric stress

$q_{\min }$ deviatoric stress at quasi-steady state, or at critical state when no quasi-steady state exists

$q_{\text {UIS }}$ deviatoric stress at undrained instability state

$\left(q / p^{\prime}\right)_{\text {UIS }}$ stress ratio at undrained instability state

$R$ roundness of particle

$R_{\text {com }}$ combined roundness

$R_{\mathrm{F}}$ roundness of fines

$R_{\mathrm{HS}}$ roundness of host sand

$r_{\mathrm{E}}$ particle flatness 
$r_{\mathrm{i}}$ radius of inscribed circle associated with surface feature of particle

$r_{\mathrm{JP}}$ aspect ratio

$r_{\max }$ radius of largest circle inscribed within a particle

$S$ major axis of particle

$\alpha, \beta$ calibrating parameters in relationship between $I_{\mathrm{c}}$ and $e$

$\varepsilon_{\mathrm{a}}$ axial strain

$\phi_{\mathrm{cs}}$ critical state friction angle

$\psi \quad$ state parameter

\section{REFERENCES}

Abbireddy, C. O. R., Clayton, C. R. I. \& Huvenne, V. A. I. (2009). A method of estimating the form of fines particulates. Géotechnique 59, No. 6, 503-511, http://dx.doi.org/10.1680/geot.2008.P.009.

Alarcon-Guzman, A., Leonards, G. A. \& Chameau, J. L. (1988). Undrained monotonic and cyclic strength of sands. J. Geotech. Engng ASCE 114, No. 10, 1089-1109.

Been, K. \& Jefferies, M. G. (1985). A state parameter for sands. Géotechnique 35, No. 2, 99-102, http://dx.doi.org/10.1680/ geot.1985.35.2.99.

Bishop, A. W. (1967). Progressive failure: with special reference to the mechanism causing it. Proceedings of the geotechnical conference, Oslo, Vol. 2, pp. 142-150.

Casagrande, A. (1971). On liquefaction phenomena. Géotechnique 21, No. 3, 197-202, http://dx.doi.org/10.1680/geot.1971.21.3.197.

Castro, G., Enos, J. L., France, J. W. \& Poulos, S. J. (1982). Liquefaction induced by cyclic loading, Report No. NSF/CEE82018. Washington, DC, USA: National Science Foundation.

Cavarretta, I., Coop, M. \& O'Sullivan, C. (2010). The influence of particle characteristics on the behaviour of coarse grained soils. Géotechnique 60, No. 6, 413-423, http://dx.doi.org/10.1680/ geot.2010.60.6.413.

Cho, G., Dodds, J. \& Santamarina, J. C. (2006). Particle shape effects on packing density, stiffness and strength: natural and crushed sands. J. Geotech. Geoenviron. Engng ASCE 132, No. $5,591-602$.

Endoh, S., Kuga, Y., Ohya, H., Ikeda, C. \& Iwata, H. (1998). Shape estimation of anisometric particles using size measurement techniques. Particle Syst. Charact. 15, No. 3, 145-149.

Georgiannou, V. N. (2006). The undrained response of sands with additions of particles of various shapes and sizes. Géotechnique 56, No. 9, 639-649, http://dx.doi.org/10.1680/geot.2006.56.9.639.

Georgiannou, V. N., Burland, J. B. \& Hight, D. W. (1990). The undrained behaviour of clayey sands in triaxial compression and extension. Géotechnique 40, No. 3, 431-449, http://dx.doi.org/ 10.1680/geot.1990.40.3.431.

Ishihara, K. (1993). Liquefaction and flow failure during earthquakes. Géotechnique 43, No. 3, 349-415, http://dx.doi.org/ 10.1680/geot.1993.43.3.349.

Jefferies, M. G. \& Been, K. (2006). Soil liquefaction: A critical state approach. New York, NY, USA: Taylor \& Francis.

Jennings, B. R. \& Parslow, K. (1988). Particle size measurement: the equivalent spherical diameter. Proc. R. Soc. London Ser. A 419, No. 1856, 137-149.

Kuerbis, R. H., Negussey, D. \& Vaid, Y. P. (1988). Effect of gradation and fines content on the undrained response of sand. In Hydraulic fill structures (ed. D. J. A. Van Zyl), Geotechnical
Special Publication No. 21, pp. 330-345. Reston, VA, USA: ASCE.

Lade, P. V. \& Yamamuro, J. A. (1997). Effect of non-plastic fines on static liquefaction on sands. Can. Geotech. J. 34, No. 6, 918-928.

Lade, P. V., Liggio, C. D. \& Yamamuro, J. A. (1998). Effects of non-plastic fines on minimum and maximum void ratios of sand. Geotech. Test. J. 21, No. 4, 336-347.

Miura, K., Maeda, K., Furukawa, M. \& Toki, S. (1998). Mechanical characteristics of sands with different primary properties. Soils Found. 38, No. 4, 159-172.

Murthy, T. G., Loukidis, D., Carraro, J. A. H., Prezzi, M. \& Salgado, R. (2007). Undrained monotonic response of clean and silty sands. Géotechnique 57, No. 3, 273-288, http://dx.doi.org/ 10.1680/geot.2007.57.3.273.

Ni, Q., Tan, T. S., Dasari, G. R. \& Hight, D. W. (2004). Contribution of fines to the compressive strength of mixed soils. Géotechnique 54, No. 9, 561-569, http://dx.doi.org/10.1680/ geot.2004.54.9.561.

Pitman, T. D., Robertson, P. K. \& Sego, D. C. (1994). Influence of fines on the collapse of loose sands. Can. Geotech. J. 31, No. 5, $728-739$.

Rouse, P. C., Fannin, R. J. \& Shuttle, D. A. (2008). Influence of roundness on the void ratio and strength of uniform sand. Géotechnique 58, No. 3, 227-231, http://dx.doi.org/10.1680/ geot.2008.58.3.277.

Santamarina, J. C. \& Cho, G. C. (2001). Determination of critical state parameters in sandy soils: simple procedure. Geotech. Test. J. 24, No. 2, 185-192.

Schofield, A. N. \& Wroth, C. P. (1968). Critical state soil mechanics. London, UK: McGraw-Hill.

Thevanayagam, S., Shenthan, T., Mohan, S. \& Liang, J. (2002). Undrained fragility of clean sands, silty sands, and sandy silts. J. Geotech. Geoenviron. Engng ASCE 128, No. 10, 849-859.

Vaid, Y. P. \& Chern, J. C. (1985). Cyclic and monotonic undrained response of sands. In Advances in the art of testing soils under cyclic loading conditions, proceedings of the ASCE convention, Detroit (ed. V. Khosla), pp. 120-147. New York, NY, USA: ASCE.

Verdugo, R. \& Ishihara, K. (1996). The steady state of sandy soils. Soils Found. 36, No. 2, 81-91.

Wadell, H. (1932). Volume, shape, and roundness of rock particles. J. Geol. 40, No. 5, 443-451.

Yang, J. (2002). Non-uniqueness of flow liquefaction line for loose sand. Géotechnique 52, No. 10, 757-760, http://dx.doi.org/ 10.1680/geot.2002.52.10.757.

Yang, J. \& Dai, B. B. (2011). Is the quasi-steady state a real behaviour? A micromechanical perspective. Géotechnique 61, No. 2, 175-184, http://dx.doi.org/10.1680/geot.8.P.129.

Yang, J. \& Sze, H. Y. (2011a). Cyclic behaviour and resistance of saturated sand under non-symmetrical loading conditions. Géotechnique 61, No. 1, 59-74, http://dx.doi.org/10.1680/ geot.9.P.109.

Yang, J. \& Sze, H. Y. (2011b). Cyclic strength of sand under sustained shear stress. J. Geotech. Geoenviron. Engng ASCE 137, No. 12, 1275-1285.

Zlatovic, S. \& Ishihara, K. (1995). On the influence of non-plastic fines on residual strength. Proc. 1st Int. Conf. Earthquake Geotech. Engng, Tokyo 1, 239-244. 